\title{
NUMERICAL CALCULATION OF SIMULTANEOUS MASS TRANSFER OF TWO GASES ACCOMPANIED BY COMPLEX REVERSIBLE REACTIONS
}

\author{
R CORNELISSE, A A C M BEENACKERS, \\ F $P$ HAN BECKUM and $W$ $P$ VAN SWAAIJ \\ Laboratory for Chemical Reactions Engineerıng Department of Chemical Engineering, Twente University \\ of Technology PO Box 217 Enschede The Netherlands \\ (Recelved 19 June 1979 accepted 1 Octoher 1979)
}

\begin{abstract}
A discretization technique is described, which makes it possible to calculate numerically mass transfer behaviour between two media in which complex chemical reactions occur To show the stability of the technique it has been applied to the industrially well-known system of simultaneous absorption or desorption of $\mathrm{H}_{2} \mathrm{~S}$ and $\mathrm{CO}_{2}$ to or from an amine solution accompanied by simultaneously occurring st rongly interfening overall chemical reaction(s) of complex, non elementary kinetics For previously published limit cases of the transfer system considered, 1 e for the single transfer of $\mathrm{H}_{2} \mathrm{~S}$ or $\mathrm{CO}_{2}$ accompanied by reversible chemical reaction, a comparison has been made with analytical and approximate solutions of previous authors The agreement is very good In studying simultaneous transfer of $\mathrm{H}_{2} \mathrm{~S}$ and $\mathrm{CO}_{2}$ on which hardly any previous work was avalable, special attention has been paid to the effects of the reversibility of the reactions involved It has beén shown how under certain conditıons due to reversibility occurrıng in the transferzone desorption takes place though absorption would be expected on basis of the driving forces This revealed that not only enhancement factors larger than unity but also smaller even negative values are possible
\end{abstract}

INTRODUCTION

In chemical reaction engineering much work has been done with respect to modelling and calculating the rate of mass transfer in absorption of gases followed by complex chemical reactions [1-10]

Recently the field of desorption from a system involving chemical reactions has also been discussed [11] However, only a few authors $[9,11]$ have dealt with simultaneous absorption or desorption of two components accompanied by reversible complex chemical reactions

A serious problem, when calculating via a mathematical model, the rate of ab- or desorption or in general of mass transfer accompanied by complex chemical reactions, is that the differential equations describing the process, can no longer be solved analytically $[10]$

Sometimes application of a linearization technique may be advantageous $[12,13]$ in finding analytical approximate solutions, but this technique may also give erroneous results [14] A suitable way to acquire results then is to calculate the rate of transfer numencally

This however is not without numerical problems concerning stability and convergence, particularly in those cases where mass transfer is cnhanced by a reaction of more than moderate rate compared to the rate of diffusion of the transferred component near the interface $[1,15]$

Although in particular cases these problems can be overcome, the authors felt that in future there would be

†Present address Shell Internationale Petroleum Maatschappiy, Treating Division, The Hague, The Netherlands a serious need to have available a generally applicable stable technique to calculate mass transfer behaviour disregarding the separation between absorption or desorption of a complex reacting system This technique must be able to cope not only with systems based on elementary reactions, which has been the issue in almost all previous publications on this subject, but also with systems dealing with complex overall reactions This technique then supplies the basis from which a computation program can be generated to describe for instance the production in a selectively operated reactor

Consequently it will be the aim of this contribution to present a discretisation technique for calculating numerically the rate of mass transfer of a complex reacting system

In order to show the stability of the technique in calculating mass transfer rates it has to be applied to a general type of mass transfer system accompanied by a general type of reaction A system involving the simultaneous transfer of two components from or to a medium where complex, in principle non elementary, reversible reactions occur with variable rates could have served as a typical example for scrutinizing the convergence behaviour of the discretization technique

However in the opinion of the authors, without reducing the value of general applicability, it would be preferable to have an issue which is closer to practice, $1 \mathrm{e}$ to apply the technique to a typical but of course more pin-pointed, industrially important reaction system, which implies as much complexity as necessary

We chose the selective simultaneous transfer of hydrogen sulphide and carbon dioxide into or out of an 
aqueous solution of a secondary or primary amine $[7$, 16-18], to serve as illustrative complex reaction system It is the basic principle of various well-known processes, licensed for (sclective) scrubbing of industrial gases

\section{CHEMISTRY}

The kınetics of this system have been reported previously $[16,19-23]$ The reaction of $\mathrm{H}_{2} \mathrm{~S}$ with an amine is reversible and instantaneous compared to mass transfer This means that, according to reaction (I) at every place in the liquid and at any time equilibrium exists between the participating components related by eqn (1)

$$
\begin{gathered}
\mathrm{H}_{2} \mathrm{~S}+\mathrm{R}_{2} \mathrm{NH} \leftrightharpoons \mathrm{R}_{2} \mathrm{NH}_{2}^{+}+\mathrm{HS}^{-} \\
\mathrm{CO}_{2}+2 \mathrm{R}_{2} \mathrm{NH} \leftrightharpoons \mathrm{R}_{2} \mathrm{NH}_{2}^{+}+\mathrm{R}_{2} \mathrm{NCOO}^{-}
\end{gathered}
$$

The net forward rate of reaction of $\mathrm{H}_{2} \mathrm{~S}$ is not defined since it represents the difference between the forward and reverse reaction of (I), both of which can be considered infinitely fast [2]

$$
\begin{gathered}
K_{\mathrm{H}_{2} \mathrm{~S}}=\left[\mathrm{HS}^{-}\right]\left[\mathrm{R}_{2} \mathrm{NH}_{2}^{+}\right] /\left(\left[\mathrm{H}_{2} \mathrm{~S}\right]\left[\mathrm{R}_{2} \mathrm{NH}\right]\right) \\
K_{\mathrm{CO}_{2}}=\left[\mathrm{R}_{2} \mathrm{NCOO}^{-}\right]\left[\mathrm{R}_{2} \mathrm{NH}_{2}^{+}\right] /\left(\left[\mathrm{CO}_{2}\right]\left[\mathrm{R}_{2} \mathbf{N H}\right]^{2}\right)
\end{gathered}
$$

The reaction (II) of $\mathrm{CO}_{2}$ has also to be considered reversible but it is in general not instantaneous with respect to mass transfer This reaction results in the formation of a carbamate $\left(\mathrm{R}_{2} \mathrm{NCOO}^{-}\right)$and an ammonium $\left(\mathrm{R}_{2} \mathrm{NH}_{2}^{+}\right)$ion The net forward redction rate of $\mathrm{CO}_{2}$ per unit of volume is given [19] by relation (3)

$$
\begin{aligned}
R= & k_{2}\left(\left[\mathrm{CO}_{2}\right]\left[\mathrm{R}_{2} \mathrm{NH}\right]\right. \\
& -\frac{1}{K_{\mathrm{CO}_{2}}} \frac{\left[\mathrm{R}_{2} \mathrm{NCOO}^{-}\right]\left[\mathrm{R}_{2} \mathrm{NH}_{2}^{+}\right]}{\left[\mathrm{R}_{2} \mathrm{NH}\right]}
\end{aligned}
$$

The concentration of the various components in (3) are the actual concentrations in the liquid which need not necessarıly be in equilibrium according to relation (2)

Both reactions are non-elementary $[16,19]$ Reaction (I) is obtained by combination of the instantaneously occurring dissociation of $\mathrm{H}_{2} \mathrm{~S}$ and protonation of the amine Reaction (II) is the result of addition of the same protonation reaction of the amine to the elementary carbamate formation of moderate rate In both cases it is permissible to represent the reaction system by overall reactions, since the basically occurring and rate-determining elementary reactions are followed by an instantaneous proton transfer

By dealing with overall reactions the amount of parameters and variables involved can be reduced substantially In case reaction (I) and (II) occur simultaneously, analogously a further simplification can be obtained by subtraction of the reaction (II) from reaction (I), thus yielding the overall reaction (III)

$$
\mathrm{H}_{2} \mathrm{~S}+\mathrm{R}_{2} \mathrm{NCOO}^{-} \leftrightharpoons \mathrm{HS}^{-}+\mathrm{R}_{2} \mathrm{NH}+\mathrm{CO}_{2}
$$

This is allowed, since the overall reaction (I) is also instantaneous However, we shall still maintain the individual reactions (I) and (II) in basic reaction system The elimination of the ammonium concentration does not allow of studying the mass transfer behaviour of either reaction (I) or (II), which in our opinion would restrict the scope of this contribution too drastically

It will be evident that when we study mass transfer behaviour under conditions in which reaction (I) and (II) occur simultaneously, it will not make any difference whether we refer to reactions (I) plus (II) or to reaction (III)

With respect to the latter it may already be disclosed that simultaneous mass transfer may be accompanied by interesting phenomena By nature of the overall reaction (III) we may imagine that simultaneous absorption or desorption might introduce counteracting effects The presence of one of the transferred components can locally suppress the transfer of the other one

The authors are aware of the fact that the bicarbonate formation (reaction (IV)) might also play a role in absorption of $\mathrm{CO}_{2}$ in an amine solution

$$
\mathrm{R}_{2} \mathrm{NH}+\mathrm{CO}_{2}+\mathrm{H}_{2} \mathrm{O} \leftrightharpoons \mathrm{HCO}_{3}^{-}+\mathrm{R}_{2} \mathrm{NH}_{2}^{+}
$$

The rate of reaction of the latter is so small, however, compared to mass transfer, that this reaction will only contribute to the composition of the bulk In order to simplify the bulk composition calculations, we shall state that the bulk contans a certain amount of ammonium bicarbonate, realizing that in reality this would be an equilıbrium-dependent parameter

For the sake of convenience the above quoted reactions are denoted for an amine of the $R_{2} \mathbf{N H}$ type, $1 \mathrm{e}$ for a secondary amine which comprises two identical aliphatic side groups Naturally the reactions will also be valıd for other secondary or primary amines Only sterically hindered secondary amines do not display the carbamate formation (II)

\section{The mass transfer model}

We shall describe mass transfer in the gasphase by means of the stagnant film model while for the liquid phase Higbie's penetration model will be used The reason for using the penetration model for the liquid phase is that for mass transfer with complex chemical reaction the penetration theory is supposed to be more realistic As no reaction takes place in the gas phase, the simple film theory can be chosen here The latter also results in a suitable form of the boundary conditions at the interface 
The phenomena of simultaneous diffusion in the gas phase and diffusion plus reversible reaction in the liquid near the interface are denoted as follows

the carbondioxide reaction balance

$$
\begin{aligned}
\frac{\partial\left[\mathrm{CO}_{2}\right]}{\partial t}= & D_{\mathrm{CO}_{2}} \frac{\partial^{2}\left[\mathrm{CO}_{2}\right]}{\partial x^{2}}-k_{2}\left[\mathrm{CO}_{2}\right]\left[\mathbf{R}_{2} \mathbf{N H}\right] \\
& +\frac{k_{2}}{K_{\mathrm{CO}_{2}}} \frac{\left[\mathbf{R}_{2} \mathrm{NCOO}^{-}\right]\left[\mathbf{R}_{2} \mathbf{N H}_{2}^{+}\right]}{\mathbf{R}_{2} \mathbf{N H}}
\end{aligned}
$$

the total carbondtoxide balance

$$
\begin{aligned}
\frac{\partial\left[\mathrm{CO}_{2}\right]}{\partial t} & +\frac{\partial\left[\mathbf{R}_{2} \mathrm{NCOO}^{-}\right]}{\partial t}=D_{\mathrm{CO}_{2}} \frac{\partial^{2}\left[\mathrm{CO}_{2}\right]}{\partial x^{2}} \\
& +D_{\mathbf{R}_{2} \mathrm{NCOO}^{-}} \frac{\partial^{2}\left[\mathbf{R}_{2} \mathrm{NCOO}^{-}\right]}{\partial x^{2}}
\end{aligned}
$$

the total sulphur balance

$$
\begin{aligned}
\frac{\partial\left[\mathrm{H}_{2} \mathrm{~S}\right]}{\partial t}+\frac{\partial\left[\mathrm{HS}^{-}\right]}{\partial t}=D_{\mathrm{H}_{2} \mathrm{~S}} \frac{\partial^{2}\left[\mathrm{H}_{2} \mathrm{~S}\right]}{\partial \mathrm{x}^{2}} & \\
& +D_{\mathrm{HS}^{-}} \frac{\partial^{2}\left[\mathrm{HS}^{-}\right]}{\partial \mathrm{x}^{2}}
\end{aligned}
$$

the total amine balance

$$
\begin{aligned}
\frac{\partial\left[\mathbf{R}_{2} \mathbf{N H}\right]}{\partial t}+\frac{\partial\left[\mathbf{R}_{2} \mathbf{N H}_{2}^{+}\right]}{\partial t}+\frac{\partial\left[\mathbf{R}_{\mathbf{2}} \mathbf{N C O O}^{-}\right]}{\partial t} \\
=D_{\mathbf{R}_{2} \mathbf{N H}} \frac{\partial^{2}\left[\mathbf{R}_{2} \mathbf{N H}\right]}{\partial x^{2}}+D_{\mathbf{R}_{2} \mathbf{N H}_{2}} \frac{\partial^{2}\left[\mathbf{R}_{2} \mathbf{N H}_{2}^{+}\right]}{\partial x^{2}} \\
+D_{\mathbf{R}_{2} \mathbf{N C O O}^{-}} \frac{\partial^{2}\left[\mathbf{R}_{2} \mathrm{NCOO}^{-}\right]}{\partial x^{2}}
\end{aligned}
$$

the acid balance

$$
\begin{aligned}
\frac{\partial\left[\mathrm{H}_{2} \mathrm{~S}\right]}{\partial t}+ & \frac{\partial\left[\mathrm{CO}_{2}\right]}{\partial t}+\frac{\partial\left[\mathbf{R}_{2} \mathrm{NH}_{2}^{+}\right]}{\partial t} \\
= & D_{\mathrm{H}_{2} \mathrm{~s}} \frac{\partial^{2}\left[\mathrm{H}_{2} \mathrm{~S}\right]}{\partial x^{2}}+D_{\mathrm{CO}_{2}} \frac{\partial^{2}\left[\mathrm{CO}_{2}\right]}{\partial x^{2}} \\
& +D_{\mathbf{R}_{2} \mathrm{NH}_{2}^{+}} \frac{\partial^{2}\left[\mathbf{R}_{2} \mathrm{NH}_{2}^{+}\right]}{\partial x^{2}}
\end{aligned}
$$

Relation (8) states that the accumulation of acid avalable in the form of $\mathrm{H}_{2} \mathrm{~S}, \mathrm{CO}_{2}$ and $\mathrm{R}_{2} \mathrm{NH}_{2}^{+}$is equal to the net inflow by diffusion of $\mathrm{H}_{2} \mathrm{~S}, \mathrm{CO}_{2}$ and $\mathrm{R}_{2} \mathrm{NH}_{2}^{+}$

Equilibrium eqn (1) replaces the reaction balance for $\mathrm{H}_{2} \mathrm{~S}$

The bulk of the liquid is assumed to be in equilibrium for a given loading of carbondioxide and hydrogensulphide Accordingly, in terms of the Higbie model, the composition of the package is denoted as follows

$$
\text { for } \begin{cases}t=0, & x \geq 0 \\ t \neq 0, & x=\infty\end{cases}
$$

$$
\left[\mathrm{CO}_{2}\right]+\left[\mathrm{R}_{2} \mathrm{NCOO}^{-}\right]=\mathrm{C}_{2}
$$

$$
\left[\mathrm{H}_{2} \mathrm{~S}\right]+\left[\mathrm{HS}^{-}\right]=\mathrm{Cl}
$$

$$
\left[\mathrm{R}_{2} \mathrm{NH}\right]+\left[\mathrm{R}_{2} \mathrm{NH}_{2}^{+}\right]+\left[\mathrm{R}_{2} \mathrm{NCOO}^{-}\right]=A m
$$

$$
\left[\mathrm{H}_{2} \mathrm{~S}\right]\left[\mathrm{R}_{2} \mathrm{NH}\right] /\left(\left[\mathrm{HS}^{-}\right]\left[\mathrm{R}_{2} \mathrm{NH}_{2}^{+}\right]\right)=1 / K_{\mathrm{H}_{2} \mathrm{~S}}
$$

$$
\left[\mathrm{CO}_{2}\right]\left[\mathrm{R}_{2} \mathrm{NH}\right]^{2} /\left(\left[\mathrm{R}_{2} \mathrm{NCOO}^{-}\right]\left[\mathrm{R}_{2} \mathrm{NH}_{2}^{\prime}\right]\right)
$$$$
=1 / K_{\mathrm{CO}} \text {. }
$$

$$
\left[\mathbf{R}_{2} \mathrm{NCOO}^{-}\right]+\left[\mathrm{HS}^{-}\right]+\left[\mathrm{HCO}_{3}^{-}\right]=\left[\mathbf{R}_{2} \mathrm{NH}_{2}^{+}\right]
$$

Equations (9)-(11) evaluate the initial loadings of the package, while eqns (1) and (2) suppose equilibrium for reaction (I) and (II) at $t=0$ and at infinite depth Equation (12) represents the electrical charge balance

The additional boundary conditions for $x=0$ and $t \geq 0$ are

$$
\begin{aligned}
& \mathrm{kg}_{2}\left(\left[\mathrm{CO}_{2}\right]_{g}-\frac{\left[\mathrm{CO}_{2}\right]}{m_{2}}\right) \\
& =\lambda-D_{\mathrm{CO}_{2}} \frac{\partial\left[\mathrm{CO}_{2}\right]}{\partial x}-D_{\mathbf{R}_{2} \mathrm{NCOO}} \frac{\partial\left[\mathbf{R}_{2} \mathrm{NCOO}^{-}\right]}{\partial x} \\
& k g_{1}\left(\left[\mathrm{H}_{2} \mathrm{~S}\right]_{g}-\frac{\left[\mathrm{H}_{2} \mathrm{~S}\right]}{m_{1}}\right) \\
& =-D_{\mathbf{H}_{2} \mathbf{S}} \frac{\partial\left[\mathrm{H}_{2} \mathrm{~S}\right]}{\partial x}-D_{\mathbf{H S}} \frac{\partial\left[\mathrm{HS}^{-}\right]}{\partial x} \\
& D_{\mathbf{R}_{2} \mathbf{N H}} \frac{\partial\left[\mathbf{R}_{2} \mathbf{N H}\right]}{\partial x}+D_{\mathbf{R}_{2} \mathbf{N H}_{2}} \frac{\partial\left[\mathbf{R}_{2} \mathbf{N H}_{2}^{+}\right]}{\partial x} \\
& +D_{\mathbf{R}_{2} \mathbf{N C O O}^{-}} \frac{\partial\left[\mathbf{R}_{2} \mathrm{NCOO}^{-}\right]}{\partial x}=0 \\
& \frac{\partial\left[\mathbf{R}_{2} \mathrm{NCOO}^{-}\right]}{\partial x}=0 \\
& D_{\mathbf{R}_{2} \mathbf{N H}} \frac{\partial\left[\mathbf{R}_{\mathbf{2}} \mathbf{N H}\right]}{\partial x}+D_{\mathbf{H S}} \frac{\partial\left[H S^{-}\right]}{\partial x}=0
\end{aligned}
$$

Relation (1) completes the set of these boundary conditions Relations (13) and (14) equal the transfer rates at the gas and liquid side of $\mathrm{CO}_{2}$ and $\mathrm{H}_{2} \mathrm{~S}$ respectively Equation (15) states that no amine can pass the interface, while eqn (16) expresses that no $\mathrm{R}_{2} \mathrm{NCOO}^{-}$can pass the interface nor can be converted infinitely fast into $\mathrm{CO}_{2}$

Equation (17) gives the analogue for $\mathrm{HS}^{-}$, but now HS $^{-}$may be converted into $\mathrm{H}_{2} \mathrm{~S}$ instantaneously, with conversion of $\mathrm{R}_{2} \mathrm{NH}_{2}^{+}$into $\mathrm{R}_{2} \mathrm{NH}$ (I) The sum of the diffusion rates at $x=0$ of $\mathrm{HS}^{-}$and $\mathrm{R}_{2} \mathrm{NH}$ therefore has to be zero 
The enhancement factors $\phi 1$ and $\phi 2$ of $\mathrm{H}_{2} S$ and $\mathrm{CO}_{2}$ respectively are defined as

$$
\begin{aligned}
& 2 \sqrt{\frac{D_{\mathbf{H}_{2} \mathrm{~S}}}{\pi \tau}}\left(\left[\mathrm{H}_{2} \mathrm{~S}\right]_{x=0}-\left[\mathrm{H}_{2} \mathrm{~S}\right]_{x=\infty}\right) \phi_{1} \\
& =\frac{1}{\tau_{0}} \int_{0}^{\tau}\left\{-D_{\mathbf{H}_{2}} \mathbf{S}{\frac{\mathrm{d}\left[\mathrm{H}_{2} \mathrm{~S}\right]}{\mathrm{d} x}}_{\mid x=0}\right. \\
& \left.-D_{\mathrm{HS}^{-}} \frac{\mathrm{d}\left[\mathrm{HS}^{-}\right]}{\mathrm{d} x}{ }_{\mid x=0}\right\} \mathrm{d} t
\end{aligned}
$$

$$
\begin{aligned}
& 2 \sqrt{\frac{D_{\mathrm{CO}_{2}}}{\pi \tau}}( {\left.\left[\mathrm{CO}_{2}\right]_{x=0}-\left[\mathrm{CO}_{2}\right]_{\mathrm{x}=\infty}\right) \phi_{2} } \\
&=\left\{\frac{1}{\tau_{0}} \int_{0}^{\tau}-\left.D_{\mathrm{CO}_{2}} \frac{\mathrm{d}\left[\mathrm{CO}_{2}\right]}{\mathrm{d} x}\right|_{\mid x=0}\right\} \mathrm{d} t
\end{aligned}
$$

where $\tau$ is the contact time of the stagnant element with the gas phase

\section{Numerlcal treatment}

For the sake of convenience in the numerical treatment of the system the equations have been transformed into a dimensionless form (see Appendix)

The numerical method for solving the parabolic differential equations is essentially the three-point backward scheme by Baker and Oliphant [24]

Accordingly the diffusion eqn (20)

$$
\frac{\partial U}{\partial \theta}=r \frac{\partial^{2} U}{\partial z^{2}}
$$

1s discretized as follows At any $z=z_{2}=z_{0}+\imath \mathrm{h}, \theta$ $=\theta_{j+1}=(j+1) k$ of a rectangular grid (Fig 1) the second derivative of $U$ with respect to $z$ is replaced by (21)

$$
\frac{\partial^{2} U_{1}^{J+1}}{\partial z^{2}}=\left(U_{\imath-1}^{J+1}-2 U_{2}^{j+1}+U_{t+1}^{j+1}\right) / h^{2}
$$

and for the time derivative of $U$ the three-point backward formula (22) is substituted

$$
\frac{\partial U_{t}^{J+1}}{\partial \theta}=\frac{3 U_{t}^{J+1}-4 U_{1}^{J}+U_{i}^{J-1}}{2 k}
$$

Here $l$ and $J$ denote respectively the number of (discrete) steps $(h)$ in distance in the observed stagnant volume away from the interface and the number of discrete steps $(k)$ in time, countıng from the moment when the liquid volume contacts the gas phase

Thus at every $z$, we obtain a linear algebraic cquation in which a linear combination of $U_{t-1}, U_{t}$ and $U_{t+1}$ at time level $\jmath+1$ is expressed in $U$ value at the previous time levels $J$ and $J-1$

Denoting the equations subsequently in natural order $\imath=0,1,2 \quad m-1$, a system of linear equations is obtained This system can be represented in the vector notation (23)

$$
A U=B
$$

$A$ being the coefficient matrix, $U$ the unknown vector $U=\left[\begin{array}{ll}U_{0}^{j+1}, U_{1}^{j+1} & U_{m-1}^{j+1}\end{array}\right]$ and $B$ the vector bult up from the right sides of the difference equations (Fig 2)

Matrix $A$ is tridiagonal It contains only non-zero entries on the main diagonal and its mutual parallels The top row and the bottom row of $A$ need further explanation In the bottom row, corresponding with $z=z_{m}$, we find that $U_{m}^{j+1} \mathrm{in}(21)$ can be replaced by the known concentration at infinite depth in the liquid, and so it can be moved to the right-side vector $B$ The top row has a linkage to the conditions at $z=z_{0}$ A boundary condition at $z=z_{0}$, given in the form of equation (24)

$$
\frac{\partial U}{\partial z}=\alpha U+\beta
$$

can be incorporated in the second order Taylor expansion of $U$ at $z=z_{0}$ (25)

$U_{1}^{J^{+1}}=U_{0}^{s^{+1}}+h \frac{\partial U^{\jmath+1}\left(z_{0}\right)}{\partial z}+\frac{h^{2}}{2} \frac{\partial^{2} U^{\jmath+1}\left(z_{0}\right)}{\partial z^{2}}+$

Substitution eqn (20) in (25) and discretising the time derivate with the three-point backward formula (22) we deduce

$$
\begin{aligned}
U_{1}^{J+1}= & U_{0}^{J+1}\left(1+h \alpha+\frac{3}{4} \frac{h^{2}}{k r}\right)+\beta h \\
& +\frac{h^{2}}{4 k r}\left(-4 U_{0}^{J}+U_{0}^{J^{-1}}\right)
\end{aligned}
$$

Consequently we see that the first and the bottom row of $A$ involve only two unknowns

Starting from the known situation at $J=0$ the system may be solved, yielding $U$ at time level $J=1$ and by repetitive substitution of this solution as starting point for the next $\jmath+1$ point, the whole scheme moves forward eventually yielding $U^{n}$ containing the concentrations $U_{t}^{n}$ at time $\theta=n k=1$ in all grid points $z_{\imath}, l=0, \quad, m-1$

The truncation error of the method is $\mathcal{O}\left(h^{2}, k^{2}\right)$, stability has been proved in [30]

\section{Extension to the full set of parabolic equations}

The basic idea explained in the previous section can be applied to the full problem At a point $z=z_{z}$ we now have to discretize five parabolic differential equations instead of one Thus system $A U=B$ becomes much larger

Every $U_{2}$ in Fig 2 is replaced by a vector $\left(p 1_{2}, b_{1}\right.$ $a 1, a 2_{1}, p_{2}, p 2_{1}$ ) representing the (dimensionless) concentrations (see Appendix I) of the six species at 


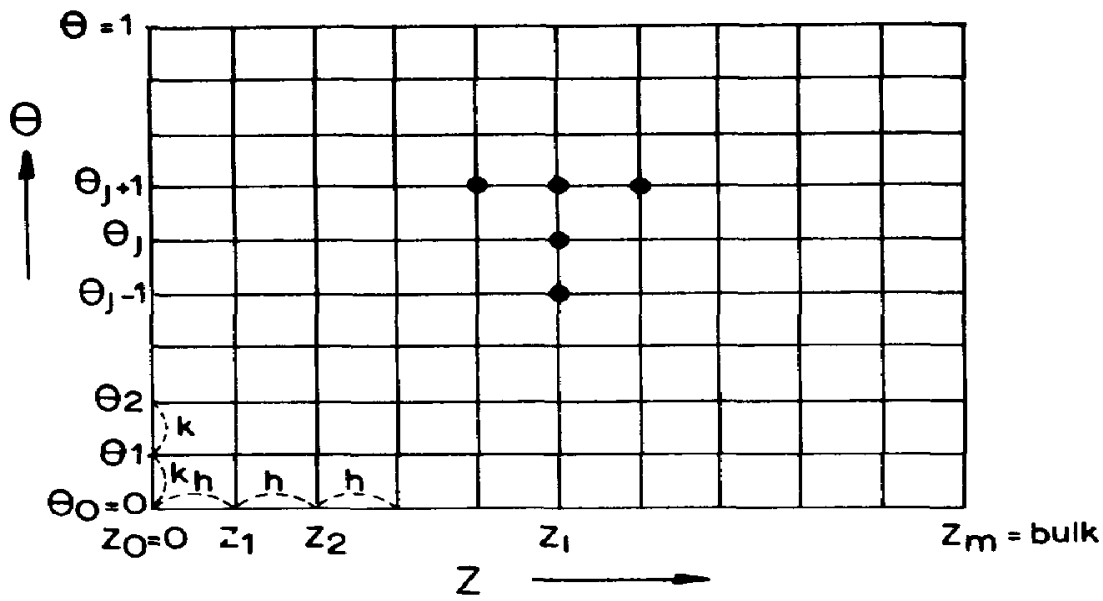

Fig 1 The time/distance space for a discrete evaluation is pictured in the form of a rectangular grid The cross points represent the discrete values of distance variable $z$ and time variable $\theta$ where the concentration vector $U_{1}^{\prime}$ is evaluated The accentuated points indicates that the discretization method connects the evaluation of $U_{i}^{t^{+1}}$ to $U_{1+1}^{+1}, U_{i-1}^{t_{1}^{+1}}, U_{j}^{t}$ and $U_{i}^{t^{-1}}$

$z=z_{1}$ and $\theta=\theta_{1+1}$ In connection with this, every element of matrix $A$ denoted by $*$ in Figure 2 is replaced by a submatrix having six columns and five rows The sixth row, which is necessary to make the whole system solvable, is supplied by the equilibrium equation (A6) Finally we have to take into account the production terms in (A3)

Both the equilibrium equation (A6) and the production terms are non linear They are linearized by the Newton-Raphson method [25]

Accordingly eqn (A6) is replaced by

$$
\begin{gathered}
-K_{1} \tilde{p} p 1+\tilde{a} 1 b+\tilde{b} a 1-K_{1} \tilde{p} 1 p \\
=\tilde{b} \tilde{a} 1-K_{1} \tilde{p} \tilde{p} 1
\end{gathered}
$$

where $\tilde{p}, \tilde{a} 1, \tilde{b}$ and $\tilde{p} 1$ are guessed values $A$ simular linearization is carried out for the production terms of (A3)
If we take $\tilde{a} 1, \tilde{b} 1$ etc equal to the value of the corresponding concentrations at the known time level $\theta$, the truncation error of this linearization is $\mathcal{O}\left(k^{2}\right)$, which is acceptable in view of the last sentence of the previous section

With $m$ intervals in $z$ direction the matrix $A$ has order $6 \mathrm{~m}$, and now possesses a band of 23 diagonals Outside these diagonals all entries are zero The specific sequence $p 1, b, a 1, a 2, p, p 2$ is found, reducing the number of diagonals from 23 to its lowest possible value of 17 For solving band matrices special subroutines can be written

\section{Iteration}

\section{FURTHER REFINEMENTS}

Although the truncation error in the linearized production term is of the same order in $k$ as the discretization error of the differential equation, we did

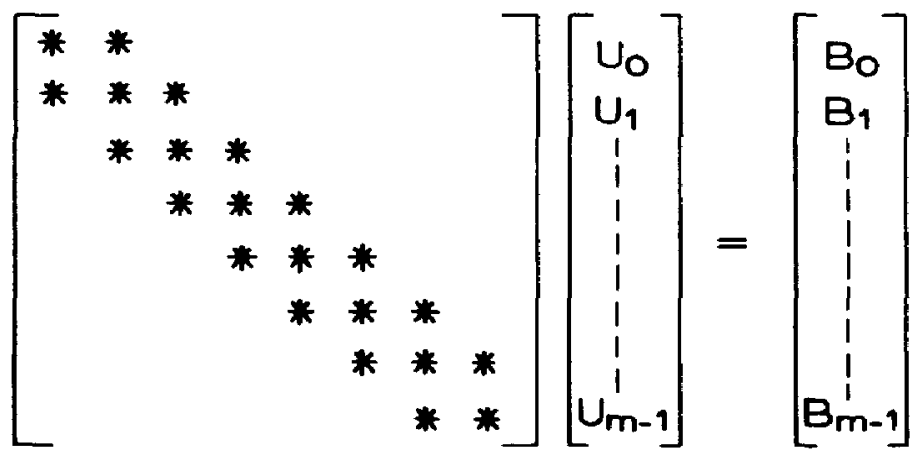

Fig 2 The discretization of the partial differential equations results in a set of linear algebraic equations, which can be represented in a vector notation $A U=B$ The shape of these vectors is depicted above Eventually upon extension to the full set of five partial differential equations (A 1)-(AS) and one equilıbrium eqn (A6) it results that every element of the vectors $U$ and $B$ is replaced by a new vector containing the concentration of the six reaction species and accordingly every element of $A$ is replaced by a $6 * 6$ submatrix 
not consider the solution vector $U$ calculated from (23) as the final solution at $\theta=\theta_{j+1}$, but only as an improved estımate of the values $\tilde{p} 1, \tilde{b}$ etc, with which the matrix $A$ and the vector $B$ are built up again Thus a new solution $U$ of system $A U=B$ is obtained and so on until the difference between two successive vectors $U$ is less than a given tolerance This iteration is of the Newton-Raphson type and exhibits quadratic convergence For a given tolerance in $U$ of $10^{-6}$ the last solution of $U$ is accurate to 12 digits Of course the accuracy still remains subject to the Baker and Oliphant truncation error $\mathcal{O}\left(h^{2}, k^{2}\right)$

\section{Transformation of $z$ and $\theta$}

Calculations have not been done with constant steps $h$ and $k$ as may have been suggested in the previous sections, but with constant steps in new space and time variables $\xi$ and $\omega$ so chosen, that the grid points of the $z, \theta$ plane $\left(F_{1} g 1\right)$ concentrate near $z=z_{0}$ where the steepest gradrents of $p 1, b$ etc occur and at small $\theta$ where the gradients of $a 1$ and $a 2$ can be expected to be maximum

Most of the computations are based on a grid with 50 points in space and 60 points in time A typical example is the following We calculated the area $0 \leq z \leq 8,0 \leq \theta \leq 1$ Here $z=8$ corresponds to 8 times the thickness of the film in terms of the film theory The value of eight was determined empirically in such a way that doubling of this value would introduce a deviation in the enhancement factors of less than one tenth of a percent

Equally spacing of $z$ and $\theta$ would give $h=016$ and $k=00167$ After transformation we have the smallest space interval 0003 and the smallest time interval 00003 , which gives a considerably more accurate description of the detalls of the concentration profiles Any two transformation functions $\xi(z)$ and $\omega(\theta)$, giving a grid point distribution of desired nature, may be chosen if only the derivative of $\xi(x)$ remains bounded in order to prevent infinite coefficients for the spatial derivatives in the differential equations and the interface conditions

Finally, $\phi_{1}$ and $\phi_{2}$ are calculated by integration by Simpson's rule using eqns (18) and (19) respectively, in which the derivatives are replaced by combination with equs (14) and (13) plus (16) respectively

In the following we shall show the results of calculations on mass transfer behaviour of this reaction system, using the above discretization technique The results will be compared with previously published analytical and approximate solutions The comparison will show the applicability of the approximate models As evidence for the stability of this discretization technique it will further be shown that variation of the dimensionless reaction parameter $M$ or equilibrium constants over more than eight decades will cause no problem concerning stability or convergence in the numerical system This result has not been publıshed before
The scope of the contribution, however, will be much wider For the first time, as far as the authors know, it will be shown how simultaneous transfer of two species is influenced by the reversibility of the reactions involved in the reaction zone, in such a way that desorption of one of the species occurs, though the driving force would predict absorption This phenomenenon of forced enhanced desorption implies that, in addition to the values of the enhancement factors larger than unity, smaller and even negative values can also occur

The possibility of negative enhancement factors has not been demonstrated before

In the previous section the phenomenon of simultaneous transfer of two gases in a liquid with counteracting reversible parallel reactions has been described and discretized to be treated numerically

However nothing has been assumed about the range of values of the various parameters included in the system, such as $k g_{1}, k g_{2}, m_{1}, m_{2}$, the diffusion coefficients, the contact time $\tau$, initial concentrations, equilıbrium constants etc Still, the assumption of these values will be the key in showing the results of the system with regard to the numerical stability and with respect to typical sorption behaviour Depending on the values of the various parameters the system describes for instance the sorption/reaction schemes as outlined in Table 1

It would be far beyond the scope of this contribution to give a complete exhibition of the influences of all the various parameters on the enhancement factors $\phi_{1}$ and $\phi_{2}$

However it is of interest to demonstrate some of the effects of reversibility on the rate of mass transfer under both absorption and desorption conditions, parallel to the confirmation of the excellent numerical properties

To restrict the number of variables the larger part of the parameters mentioned above will not be varied and, unless specified elsewhere, they are evaluated to practical values as given in Table 2

The value of $\tau$ is chosen arbitrarily, in the light of the fact that the solution of the system also provides sixty solutions at shorter tıme levels These solutions will not be shown The diffusivities are all taken equal, allowing of a good comparison with the results of previous contributions based on different transfer models To ensure total liquid-phase resistance to mass transfer the mass transfer coefficients of $\mathrm{CO}_{2}$ and $\mathrm{H}_{2} \mathrm{~S}$ in the gas phase are stated to be $100 \mathrm{~m} / \mathrm{s}$ However, in those cases where only one of the gas phase components is desired to be transferred the $\mathrm{kg}$ of the not-transferred component will be taken as zero

The concept now is that enhancement factors $\phi_{1}$ and $\phi_{2}$ are a function of $M, K_{\mathrm{H}_{2} \mathrm{~S}}, K_{\mathrm{CO}_{2}}, \alpha 1$ and $\alpha 2$

The latter two symbols stand for the molar sulphur and carbon-dioxide load per mole amine

Some particular results will be shown for the following cases of Table 1 (a) scheme 5, which also 
Table 1 The Studied simultaneous transfer of $\mathrm{H}_{2} \mathrm{~S}$ (Al) and $\mathrm{CO}_{2}(\mathrm{~A} 2)$ accompanied by reaction with an amine $\mathbf{R}_{2} \mathbf{N H}$ (B) which yields conversion of $\mathbf{H S}^{-}$(P1) $\mathbf{R}_{2} \mathrm{NH}_{2}^{+}$(P) and $\mathbf{R}_{2} \mathrm{NCOO}^{-}$(P2) comprises several mass transfer regimes as indicated in the table below The various regimes can be generated by appropriate evaluation of the parameters involved The values used in this contribution are indicated The values given between brackets are arbitrarly set

\begin{tabular}{|c|c|c|c|c|c|c|c|c|c|}
\hline scheme & $\begin{array}{l}\text { uverall } \\
\text { reaction } \\
\text { involved }\end{array}$ & $\mathrm{k}_{1}$ & $k_{2}$ & M & alo & $\sqrt{72}$ & $k \mathfrak{g}_{1}$ & $\mathrm{~kg} g_{2}$ & mass transfer regumo \\
\hline 1 & $A \perp(g)=A \perp(1)$ & 0 & $\left(10^{-4}\right)$ & $\left(10^{-2}\right)$ & 1,1 & $\left(\begin{array}{ll}8 & 0\end{array}\right)$ & 0 & (0) & physical ab/de-sorption of \\
\hline 2 & $A 2(g)=A 2(1)$ & $\left(10^{6}\right)$ & 0 & 10011 & $(0)$ & $<1>1$ & $(0)$ & 0 & physical $_{2}$ ab, de-sorption of \\
\hline 3 & $\mathrm{~A}_{1}+\mathrm{B} \longrightarrow$ & $\infty$ & $\left(10^{-4}\right)$ & $\left(10^{-2}\right)$ & 0 & $\left(\begin{array}{ll}8 & 06\end{array}\right)$ & $>0$ & (0) & $\begin{array}{l}\text { absorption of A } 1 \text { followed } \\
\text { by instantaneous chemical } \\
\text { reactions }\end{array}$ \\
\hline 4 & $\mathrm{~A} 2+2 \mathrm{~B} \longrightarrow$ & $\left(10^{6}\right)$ & $\infty$ & $>0$ & 101 & 1 & $(0)$ & 0 & $\begin{array}{l}\text { absarption of A2 followed } \\
\text { by Irreversible } 1 \text { order } \\
\text { reaction of variable rate }\end{array}$ \\
\hline 5 & $A 1+B \leftrightharpoons P 1+P$ & $>0$ & $\left(10^{-4}\right)$ & $\left(10^{-2}\right)$ & $<1,1$ & $\left(\begin{array}{ll}8 & 06\end{array}\right)$ & 0 & 103 & $\begin{array}{l}\text { ab/de-sorption of } A l \text { accom } \\
\text { parted by lishantaneus te- } \\
\text { verstble reaction }\end{array}$ \\
\hline 6 & $\mathrm{~A} 2+2 \mathrm{~B} \leftrightharpoons \mathrm{P} 2+\mathrm{P}$ & $\left(10^{6}\right)$ & $>0$ & o & (0) & 1 & 10. & 0 & $\begin{array}{l}\text { abide-sozption of } \overline{A 2} \text { accom- } \\
\text { panled by reversible reaction } \\
\text { of variable rate }\end{array}$ \\
\hline 7 & $\begin{array}{l}A_{1}+P_{2}= \\
A 2+P_{1}+B\end{array}$ & 0 & 0 & 0 & 0 & 0 & 0 & 0 & $\begin{array}{l}\text { Slmultaneous sorption of Ai } \\
\text { and A2 accompanied by a re- } \\
\text { versible chemical reaction } \\
\text { with complex kinetics }\end{array}$ \\
\hline 8 & $\begin{array}{l}A 1+P_{2}= \\
A 2+P 1+B\end{array}$ & $>0$ & $>0$ & 0 & 0 & 0 & 0 & 0 & $\begin{array}{l}\text { sorption of al accompanied bu } \\
\text { a reversible overall reaction } \\
\text { with comblex kinetics (A2 not } \\
\text { volatile) }\end{array}$ \\
\hline 9 & $\begin{array}{l}A 2+P_{1}+B \longrightarrow \\
A 1+P 2\end{array}$ & $>0$ & $>0$ & 0 & 0 & 0 & 0 & 0 & $\begin{array}{l}\text { sorption of AZ accompanied by } \\
\text { a reverable rcaction with } \\
\text { complex kinetics (Al not } \\
\text { volatile) }\end{array}$ \\
\hline
\end{tabular}

covers in continuity the limit schemes 1 and 3 , (b) scheme 6, which also covers in continuity the limit schemes 2 and 4 , (c) scheme 7

(a) Sorption of a single component $\left(H_{2} S\right)$ followed by instantaneous reversible reaction at various liquid loadings ( $\alpha 1) A 1+B \leftrightharpoons P+P 1$

By putting $k g_{2}=0, M=10^{-2}, K_{\mathrm{CO}_{2}}=10^{-4}$ and $\alpha 2=10^{-2}$, the model reduces to mass transfer of one component $\left(\mathrm{H}_{2} \mathrm{~S}\right)$ with instantaneous reaction only (Table 4, Scheme 5) Enhancement factor $\phi_{1}$ is a function of $K_{\mathrm{H}_{2} \mathrm{~S}}$ and $\alpha 1$ (Fig 3) only Figure 3 shows $\phi_{1}$ as function of $K_{\mathrm{H}_{2} \mathrm{~s}}$ at various values of $\alpha 1$

Every solid line represents a curve for constant $\alpha 1$ For very small values of $\mathrm{K}_{\mathrm{H}_{2} \mathrm{~S}}$ the reaction between $\mathrm{H}_{2} \mathrm{~S}$ and free amine does not occur Sulphur is avalable only in the form of $\mathrm{H}_{2} \mathrm{~S}$ The liquid acts as physical solvent (Table 1, Scheme 1) $\phi_{1}$ equals unity for all $\alpha 1$ both for both absorption and desorption

For infinite values of $K_{H_{2} S}$ the system reflects absorption followed by instantaneous irreversible reaction (Scheme 3) The enhancement factor,

Table 2 List of parameters entailed in the system, which are prefixed These parameters are evaluated to practical values as indicated above

\begin{tabular}{|c|c|c|}
\hline parameter & value & dimension \\
\hline$T$ & $87 * 10^{-4}$ & $\mathrm{~s}$ \\
$\mathrm{Am}$ & 20 & $\mathrm{kmole} / \mathrm{m}^{3}$ \\
$\mathrm{~m}_{1}$ & 1805 & $-/-$ \\
$\mathrm{m}_{2}$ & 0595 & $-/-$ \\
{$\left[\mathrm{H}_{2} \mathrm{~S}_{\mathrm{g}} \mathrm{g}\right.$} & 417 & $\mathrm{kmole} / \mathrm{m}^{3}$ \\
{$\left[\mathrm{CO}_{2}{ }^{\mathrm{g}}\right.$} & 417 & $\mathrm{kmole} / \mathrm{m}^{3}$ \\
$\mathrm{D}_{\mathrm{CO}_{2}}$ & $53 * 10^{-10}$ & $\mathrm{~m}^{2} / \mathrm{s}$ \\
$\mathrm{I}_{1}$ & 1 & $-/-$ \\
$\mathrm{kg}_{1}$ & 100 & $\mathrm{~m} / \mathrm{s}$ \\
$\mathrm{kg}_{2}$ & 100 & $\mathrm{~m} / \mathrm{s}$ \\
$\mathrm{p}^{3}$ & 002 & $-/-$ \\
\hline
\end{tabular}




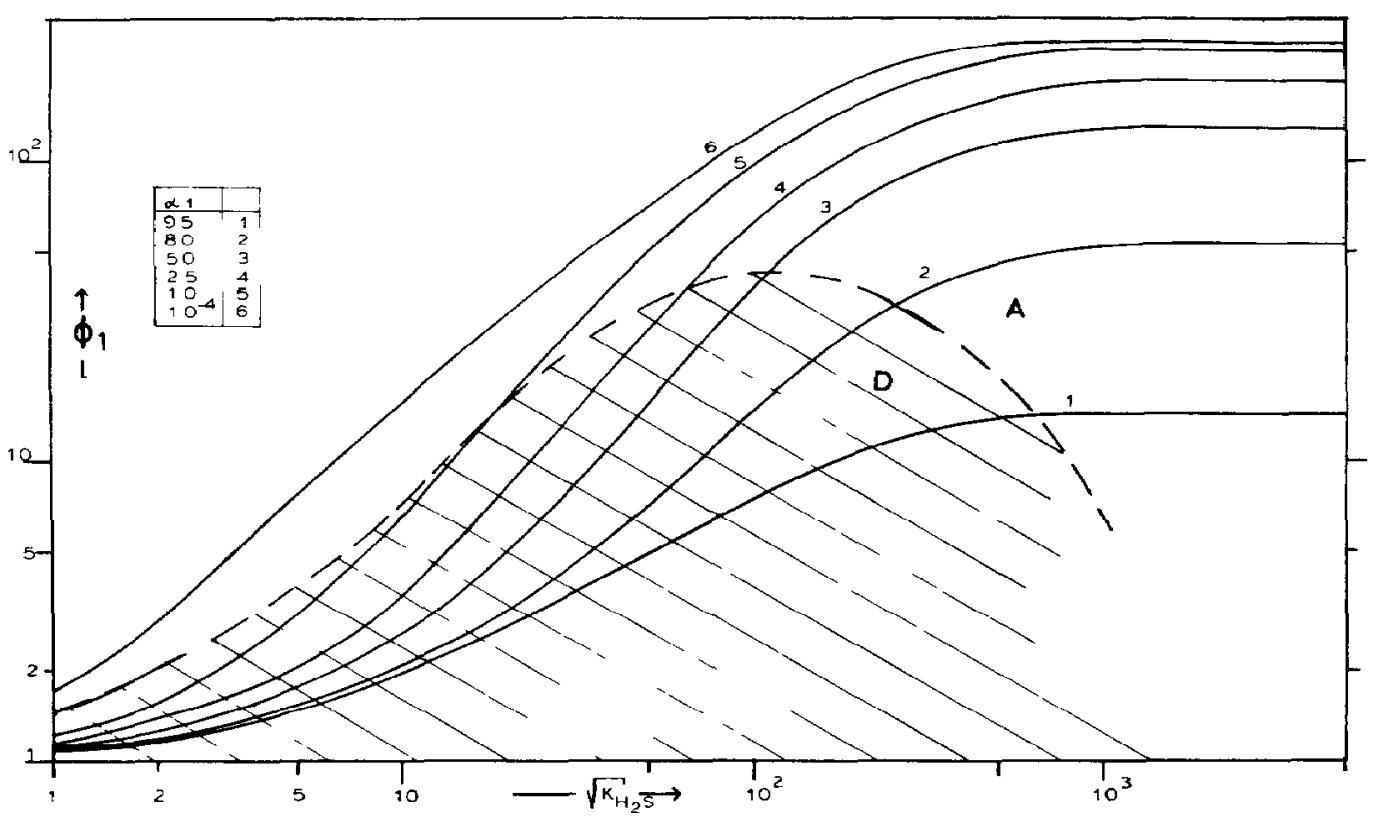

Fig 3 Plot of the enhancement factor of $\mathrm{H}_{2} \mathrm{~S}\left(\phi_{1}\right)$ as a function of the equilibrium value $K_{\mathrm{H}_{2} \mathrm{~S}}$ for various sulphur loadings $\alpha 1$ of the solvent The plot holds for the conditions as specified in Table 1 (for Schemes 1, 3 and 5) and Table 2 Depending on the value of $K_{\mathbf{H}_{2} \mathrm{~s}}$ under these conditions absorption or desorption (dashed area) can occur The dashed line represents the conditions where no net mass transfer occurs since the gas and liquid phase are in equilibrium $(a 1=1)$

calculated numerically, almost exactly meets the theoretically calculated value for this regime

$$
\phi_{1}=1+\frac{\left[\mathbf{R}_{2} \mathrm{NH}\right]}{m_{1}\left[\mathrm{H}_{2} \mathrm{~S}\right]_{g}}
$$

where $\left[\mathbf{R}_{2} \mathbf{N H}\right]$ stands for the free amine concentratron

For intermediate values of $K_{\mathrm{H}_{2} \mathrm{~S}}$, analytical solutions are also avallable Secor and Beuttler [26] and recently also Onda et al [5] gave a general analytical solution Olander [2] and Ramachandran [9] presented more particular solutions, which can be derived from the former two The difference between the numerical solution (Fig 3) and that obtained via Onda et al [5] is less than $1 \%$

In Fig 3 two regimes are shown The dashed area represents that of desorption $\left(a 1_{\infty}>1\right)$ and the region above that of absorption $\left(a 1_{\infty}<1\right)$ A dynamic equilibrium of no net mass transfer occurs for $a 1=1$ The line for $a 1_{\infty}=1$ shows a maximum at an intermediate value of $K_{\mathbf{H}_{2} \text { s }}$ In conformity with this line (though not shown) lines of $a 1_{r}=$ constant can also be generated They likewise display a maximum This means that at the same driving force liquid phase controlled desorption of $\mathrm{H}_{2} \mathrm{~S}$ goes faster for a relatively weak base like dissopropanolamine than for a strong base like monoethanolamine The occurrence of the maximum can be well understood, taking into account the free amine concentration in the bulk, which results from a specified equilibrium constant and the driving force $\left(a 1_{\infty}-1\right)$ We conclude that the numerical solution is in good agreement with the analytical solution and that the solutions of Secor and Beuttler [26], Onda et al [5], Ramachandran [9] and Olander [2] hold for both absorption and desorption

(b) Absorption or desorption accompanied by reversible reaction of finte rate $(A 2+2 B \leftrightharpoons P+P 2)$

Analogous to the former case, putting $k g_{1}=0$, $K_{\mathrm{H}_{2} \mathrm{~S}}=10^{+6}$ and $\alpha 1=001$ results in the transfer of $\mathrm{CO}_{2}$ without interference of $\mathrm{H}_{2} \mathrm{~S}$ (Table 1, Scheme 6) Since the reaction of $\mathrm{CO}_{2}$ is of finite rate, the dimensionless rate constant $M$ is a parameter too, together w1th $K_{\mathrm{CO}_{2}}$ and $\alpha 2$

To reduce the amount of parameters $\alpha 2$ has not been varied and is stated to be equal to 001 Figure 4 shows the enhancement factor $\phi_{2}$ as a function of $\sqrt{ } M$ at various values of $K_{\mathrm{CO}_{2}}$ For $K_{\mathrm{CO}_{2}} \ll 10^{-5}$ no substantial conversion of $\mathrm{CO}_{2}$ can occur in the liquid owing to equilıbrium constraints, and, independently of the value of $M$, unenhanced mass transfer always occurs $\phi_{2}$ equals unity (Table 1, Scheme 2) For very large values of $K_{\mathrm{Co}_{2}}, \phi_{2}$ reaches its limit value for instantaneous reaction, the area where kinetics of the reverse reaction and equilibrium constraints do not play a role (Table 1 , Scheme 4) Many authors have published for the case of infinite values of $K_{\mathrm{CO}_{2}}$ [5, 12, $13,27-29$ ] Some of them gave identical solutions [ 5 , $12,13]$ Wellek et al [28] recently gave a comparison of the solutions presented by the various authors We have restricted ourselves to comparing our results with 


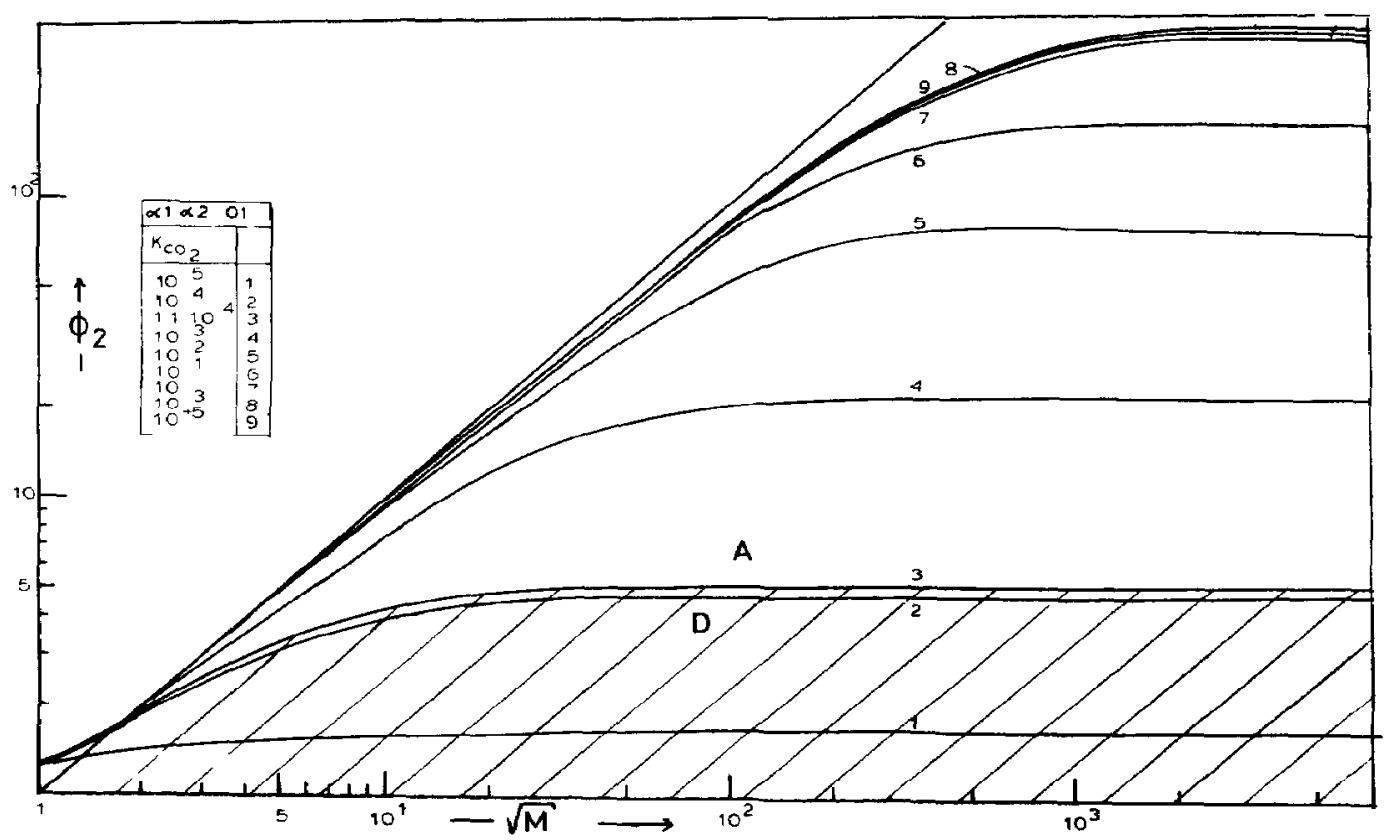

Fig 4 Plot of the cnhancement factor of $\mathrm{CO}_{2}\left(\phi_{2}\right)$ as a funciun of the dimensionless reaction rate constant $(M)$ for various values of the equilibrium constant $\left(K_{\mathrm{CO}_{2}}\right)$ The plot holds for the conditions as specified in Table 1 (for Scheme 2, 4 and 6) and Table 2 Depending on the value of $K_{\mathrm{CO}_{2}}$, absorption or desorption (dashed area) can occur No net mass transfer occurs when gas and liquid phases are in equilibrium $\left(K_{\mathrm{CO}_{2}} \simeq 14 * 10^{-4}\right)$

those of Hikita [12] and DeCoursey [27] The difference amounts to less than $3 \%$ for both

Another well-known area indicated in $F_{1 g} 4$ is that where $M$ becomes infinite, $1 \mathrm{e}$ where $\phi_{2}$ reaches its limit value for instantaneous reversible reaction for the reaction type

$$
A_{2}+2 B \leftrightharpoons P+P_{2}
$$

(analogous to Scheme 3 of Table 1 but for different stoechiometry) Here too several authors $[5,9,26,30]$ have published previously Secor and Beuttler [26], Onda et al [5], presented a solution from which the particular solutions of Danckwerts [30] and Ramachandran [9] can also be derived The difference between the present numerical solution and that of Onda [5] is less than 1\% (see Table 3)

For varying $M$ and $K$ no analytical (approximate) solutions are avallable The $\mathrm{CO}_{2}$ type kinetics are of a non elementary type No publications are avalable on this subject An approximate solution was derived based on that of Onda [ 5 ], his eqn (17) being modified to make it applicable to the more complex kinetics discussed in this paper (see eqn 29)

$$
M=M\left(\frac{b_{1}}{q_{B}}\right)\left(1+\frac{m+1}{q+1} \frac{v_{E}}{r_{E}} T\right)
$$

(nomenclature according to Onda)

In spite of this rather crude linearization the agreement found for the circumstances as applied in this contribution, was remarkable The maximum deviation was $7 \%$
In Fig 4 two areas have been indicated too The dashed area represents the area where desorption occurs, the area above that of absorption Under the

Table 3 Comparison of numerically and analytically [6] calculated values of $\phi_{2}$ for instantaneous reversible reaction of type $A 2+2 B \leftrightarrows P+P 2$ as a function of the equilibrium constant $K_{C O}$ Table 7 Schemes 24,6 For conditions applied, reference is made to Fig 4

\begin{tabular}{|c|r|r|}
\hline $\mathrm{K}_{\mathrm{CO}_{2}}$ & $\Phi_{2,}{ }^{\mathrm{nura}}$ & $\phi_{2}$, anal \\
\hline $10^{5}$ & 3851 & 3835 \\
$10^{3}$ & 3813 & 3799 \\
$10^{1}$ & 348.4 & 347.1 \\
$10^{-1}$ & 182.5 & 1825 \\
$10^{-2}$ & 79.7 & 794 \\
$10^{-3}$ & 2330 & 2316 \\
$2.98 * 10^{-4}$ & 10.35 & 1028 \\
$1.69 * 10^{-4}$ & 7.17 & 712 \\
$1.44 * 10^{-4}$ & 643 & 6.39 \\
$1.11 * 10^{-4}$ & 539 & 5.36 \\
$10^{-4}$ & 502 & 5.00 \\
$10^{-5}$ & 1.69 & 169 \\
\hline
\end{tabular}


prevailing conditions the system is approximately in dynamic equilibrium for $K_{\mathrm{CO}_{2}}=1410^{-4}$ For this $K_{\mathrm{CO}_{2}}$ no net transfer of $\mathrm{CO}_{2}$ occurs but enhancement factor $\phi_{2}$ still increases with $M$ The "dynamicity", i e the rate of equalizing a small disturbance from the equilibrium between the concentration of $\mathrm{CO}_{2}$ in the gas and liquid phase, depends on the value of $M$ and is materialized in the value of $\phi_{2}$ Here again we conclude that the solutions of Onda et al [17], Danckwerts [30], Ramachandran [9] and Secor et al [26] can be applied to both dbsorption and desorption

(c) Simultaneous absorption of two gases in a reactive liquid, one gas $\left(\mathrm{H}_{2} \mathrm{~S}\right)$ reacting instantaneously, the other with variable rate Both reactions are in principle of reversible nature (Table 1 , Scheme 7) $A 1+P 2$ $\leftrightharpoons P 1+B+A 2$

In the chemistry section we have already pointed out that at simultaneous mass transfer the two overall reactions I and II can be combined into overall reaction III

The occurrence of this overall reaction III implies that in the presence of a driving force for both $\mathrm{H}_{2} \mathrm{~S}$ and $\mathrm{CO}_{2}$ the gas and liquid phase will "try" to reach equilibrium by mass transfer of components which show up at different sides of the reaction equation III By this characteristic counteracting effects can be expected if both $\mathrm{CO}_{2}$ and $\mathrm{H}_{2} \mathrm{~S}$ display the same sign for the driving force and cooperative effects when the signs of the driving forces are different Another aspect which emerges from reaction III is that it will be impossible to generate a condition which allows both $\mathrm{H}_{2} \mathrm{~S}$ and $\mathrm{CO}_{2}$ to react irreversibly if the reaction rate of this overall reaction is instantaneous to mass transfer At instantaneous reaction equilibrium III will be established not only in the bulk of the liquid but also in the transfer zone near the interface Consequently in the transfer zone too only one condition can be fulfilled at once The equilibrium according to reaction III can lie either entirely to the right or to the left This means that e1ther $\mathrm{H}_{2} \mathrm{~S}$ or $\mathrm{CO}_{2}$ can be absorbed without back pressure limitation, $1 \mathrm{e}$ reversibility effects near the interface

It can even be imagined that, when $\mathrm{H}_{2} \mathrm{~S}$ absorption is followed by reaction III which lies entirely to the right, the induced $\mathrm{CO}_{2}$ production (back pressure) in the transfer zone might be so huge that the $\mathrm{CO}_{2}$ concentration in the transfer zone will locally overshoot the value which is in equilibrium with the concentration in the gas phase In this case $\mathrm{CO}_{2}$ will desorb, though the driving force between gas and liquid phase would predict absorption

For moderate reaction rates, the equilibrium III might not be reached in the transfer zone, especially when the driving forces are large This will result in a "pseudo" irreversibility for both reactions with respect to mass transfer The reaction rate in this case is not sufficiently fast compared to the transfer rate of the gases, that a back pressure can be built up which has a substantial impact on the transfer rate

In the following we shall show this phenomenon of pseudo irreversibility for the transfer of $\mathrm{CO}_{2}$ at moderate reaction rates in the event of the transfer of $\mathrm{H}_{2} \mathrm{~S}$ generating various degrees of depletion via its equilıbrium constant ( $K_{\mathrm{H}_{2} \mathrm{~S}}$ ) In addition we shall show the occurrence of reversibility in the transfer zone for a virtually infinite reaction rate

Figure 5 demonstrates enhancement factor $\phi_{2}$ at moderate values of $M$ for various values of $K_{\mathrm{H}_{2} \mathrm{~S}}$ It shows the effects on the transfer rate of $\mathrm{CO}_{2}$ for $K_{\mathrm{CO}_{2}}=10^{5}$ for various degrees of depletion of the amine near the interface The degree of depletion for these cases is dictated by the value of $K_{\mathrm{H}_{2} S}$ For $K_{\mathrm{H}_{2} \mathrm{~S}}<10^{-2}$ no $\mathrm{H}_{2} \mathrm{~S}$ can be converted into $\mathrm{HS}^{-}$and the amme concentration is not depleted

The $\phi_{2}$ curve reflects the enhancement factor for pseudo first order irreversible reaction (see also Table 1 , Scheme 3, as discussed above)

Increasing $K_{\mathrm{H}_{2} \mathrm{~S}}$, however, decreases the slope of the $\phi_{2}$ curve The dictated depletion causes the effective amine concentration as "experienced" by $\mathrm{CO}_{2}$ to be lower than for the pseudo first order irreversible regime

Finally, for infinite values of $K_{\mathrm{H}_{2} \mathrm{~s}}\left(K_{\mathrm{H}_{7} \mathrm{~S}}>3110^{5}\right)$ complete depletion of the amme is induced The slope of $\phi_{2}$ does not decrease further with increasing $K_{\mathrm{H}, \mathrm{S}}$

For this regime of $\mathrm{CO}_{2}$ absorption with complete depletion of amine approximate analytical solutions are also avalable Goettler and Pigford [7], Ouwerkerk [7] and Cornelisse et al [14] presented an approximate solution for simultaneous mass transfer of $\mathrm{H}_{2} \mathrm{~S}$ and $\mathrm{CO}_{2}$ under irreversible conditions at instantaneous reaction of $\mathrm{H}_{2} \mathrm{~S}$

Up to $M=10^{3}$ the difference between the present numerical solution and the approximate solution is less than $3 \%$ This shows that the assumption of pseudo irreversible conditions is valid for the conditions as applied in this contribution For $M>10^{3}$, however, deviations increase drastically This is duc to the influcnce of reversibility in the transfer zone of reaction III, which the numerical solution takes into account, whereas the approximate analytical solutions do not The simultaneous absorption of $\mathrm{H}_{2} \mathrm{~S}$ induces conditions in the transfer zone which force the $\mathrm{CO}_{2}$ absorption to occur under reversible conditions The reversibility is forced since under single transfer of $\mathrm{CO}_{2}$ under the same conditions as studied here no reversibility effects would have been experienced (see Fig 4)

To show this phenomenon of forced reversibility of $\mathrm{CO}_{2}$ in a more pronounced manner Figs 6 and 7 are given For $K_{\mathrm{CO}_{2}}=68$-a value which may occur in practice-Fig 6 shows that $\mathrm{CO}_{2}$ absorbs virtually unenhanced for $M=10^{-2}$ For $M=10^{4}$ however the picture becomes entirely different Though for $M=10^{4}$ and $K_{\mathrm{CO}_{2}}=68 \mathrm{~F} 1 \mathrm{~g} 4$ would expect $\phi_{2}$ to have a value of about 70 -which means that, in the absence of transfer of $\mathrm{H}_{2} \mathrm{~S}, \mathrm{CO}_{2}$ absorption would be 


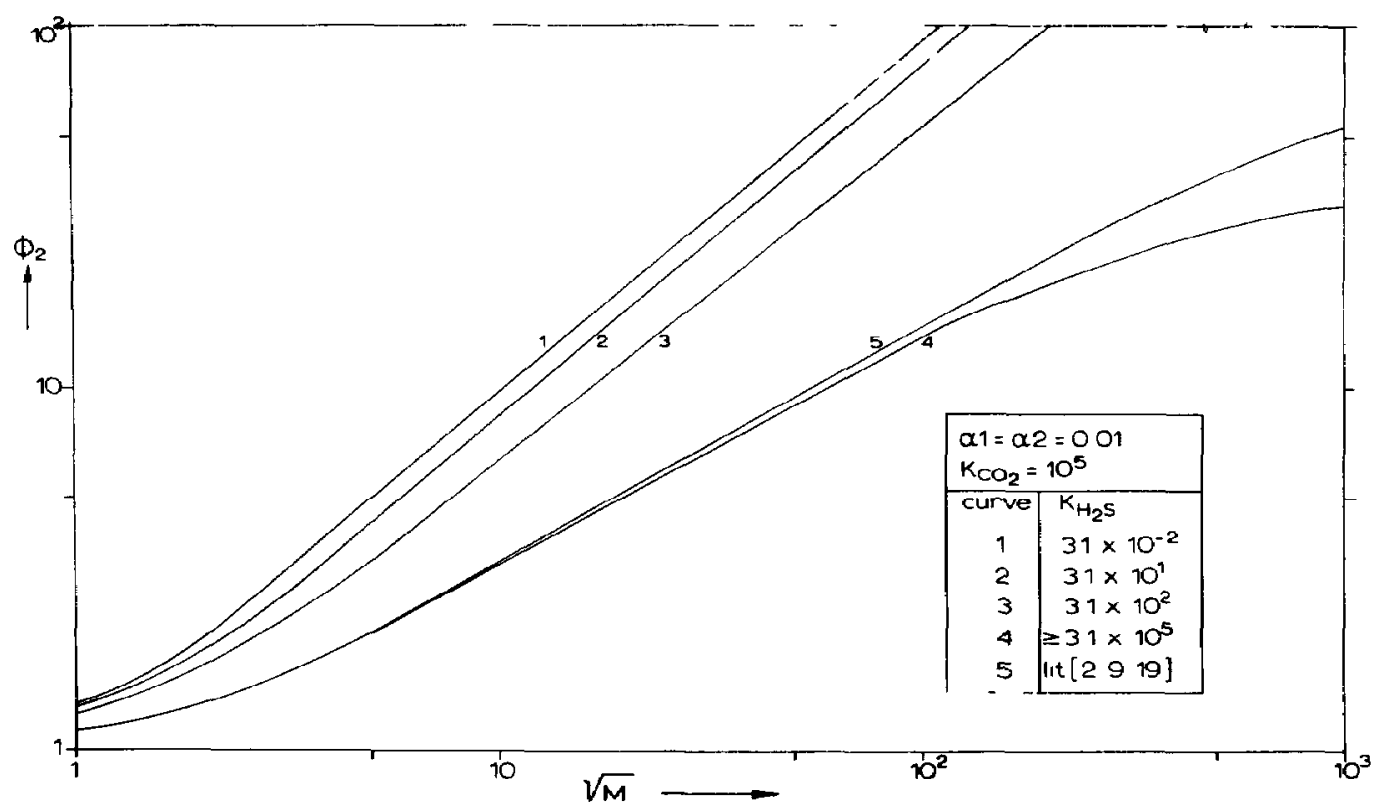

Fig 5 Plot of the enhancement factor $\phi_{2}$ as a function of the dimensionless reaction rate parameter (M) for various degrees of depletion of amine near the interface Table 1, Scheme 7 The depletion is induced by the simultaneous absorption of $\mathrm{H}_{2} \mathrm{~S}$ The degree of depletion depends on the value of the equilibrium constant of $\mathrm{H}_{2} \mathrm{~S}\left(\mathrm{~K}_{\mathrm{H}_{2} \mathrm{~S}}\right)$ The numerical solution 4, deviates from the solutions of previous workers [1, 7, 14] owing to take nio account reversibilit y efleats in the transfes zone which previous hiterature does not take into account The plot holds for conditions as outined in Table 2

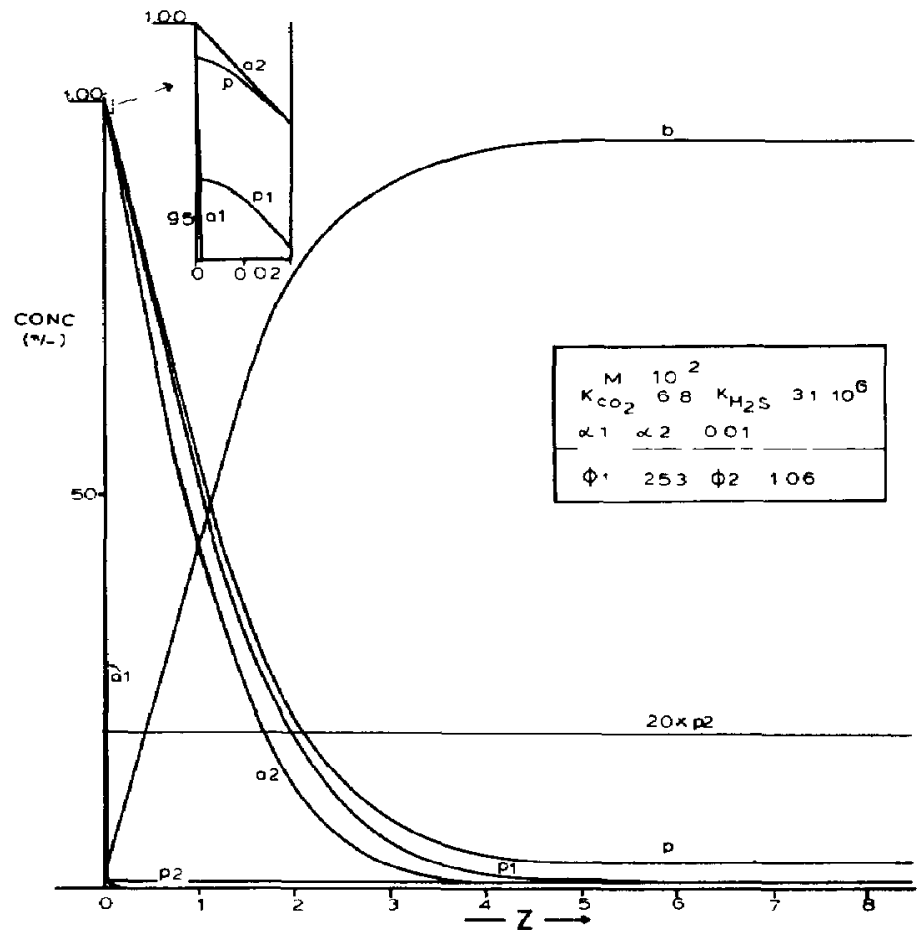

Fig 6 Dimensionless concentration profile at $\theta=1$ for simultaneous absorption of $\mathrm{H}_{2} \mathrm{~S}(a 1)$ and $\mathrm{CO}_{2}(a 2)$ accompanied by instantaneous reaction with the amine (b) for $\mathrm{H}_{2} \mathrm{~S}$ and slow reaction of for $\mathrm{CO}_{2} \mathrm{The}$ simultaneous case is in behaviour virtually identical with the sum of single $\mathrm{H}_{2} \mathrm{~S}$ and $\mathrm{CO}_{2}$ transfer without

interference by reaction The conditions applied are those denoted in Table 2 and in the plot itself 


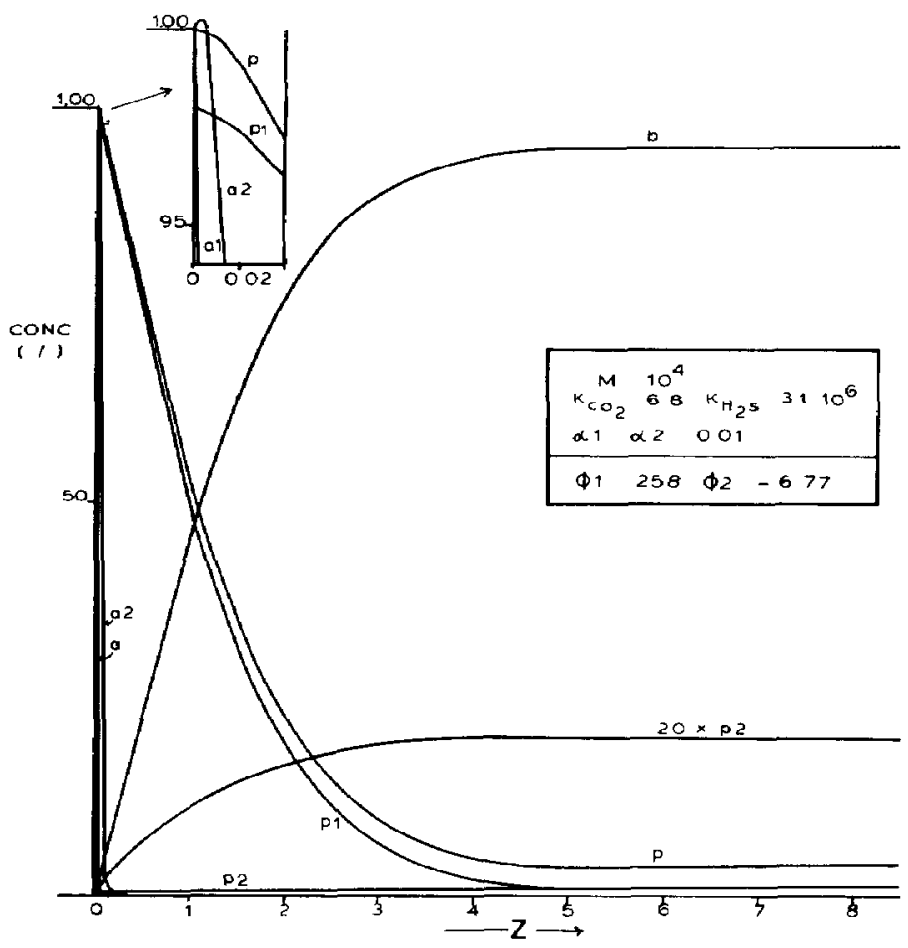

Fig 7 Numerically calculated dimensionless concentration profile at $\theta=1$ for simultaneous transfer of $H_{2} S$ (a1) and $\mathrm{CO}_{2}(a 2)$ accompanied by instantaneous reaction with the amine $(b)$ of $\mathrm{H}_{2} \mathrm{~S}$ and fast reaction for $\mathrm{CO}_{2}$, Table 1, Scheme 7 Though the driving forces, $\left(1-a 1_{\infty}\right)$ and $\left(1-a 2_{\infty}\right)$, would predict both gases would absorb as in Fig 6, interfacial reversibility induced by the conversion of $\mathrm{H}_{2} \mathrm{~S}$ causes $\mathrm{CO}_{2}$ to desorb This phenomenon of forced desorption materializes in the occurrence of a negative enhancement factor The conditions applied are the same as for Fig 6

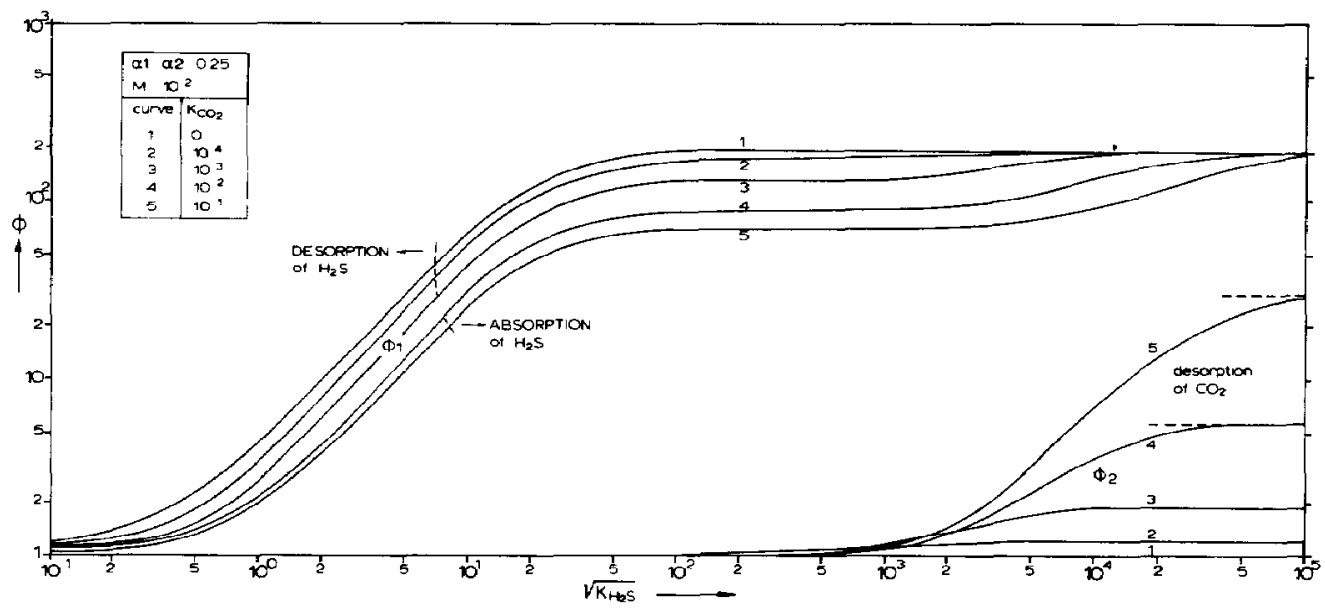

Fig 8 Plot of the enhancement factors of $\mathrm{H}_{2} \mathrm{~S}\left(\phi_{1}\right)$ and $\mathrm{CO}_{2}\left(\phi_{2}\right)$ as a function of the equilibrium constant of $\mathrm{H}_{2} \mathrm{~S}\left(K_{\mathrm{H}_{2} \mathrm{~s}}\right)$ for simultaneous transfer of $\mathrm{H}_{2} \mathrm{~S}$ and $\mathrm{CO}_{2}$ accompanied by chemical reaction Table 1 Scheme 7 $\mathrm{CO}_{2}$ desorbs while $\mathrm{H}_{2} \mathrm{~S}$ switches (dashed line) from desorption to absorption with increasing $K_{\mathrm{H}_{2} \mathrm{~S}}$ The figure shows that though the reaction rate of $\mathrm{CO}_{2}$ is slow at irreversible $\mathrm{H}_{2} \mathrm{~S}$ absorption $\mathrm{CO}_{2}$ will desorb "overenhanced" or even infinitely "overenhanced" by cooperative and forced conversion of the carbamate near the interface The sensituvity to overenhancement is dependent on the value of $K_{\mathrm{CO}_{2}}$ The conditions applied are those indicated in Table $2(\operatorname{excl~} p 3=0)$ and the above figure 
chemically enhanced by a factor of 70 - to the contrary Fig 7 reveals that in the presence of $\mathrm{H}_{2} \mathrm{~S}$ sorption/reaction $\mathrm{CO}_{2}$ will desorb enhanced by a factor of 677 Durıng the contact time $\theta$ a back pressure of $\mathrm{CO}_{2}$ is induced near the interface that overshoots the $\mathrm{CO}_{2}$ pressure in the gas phase and net desorption follows Owing to the positive driving force for $\mathrm{CO}_{2}$ absorption at $\theta=0$, and an average net desorption of $\mathrm{CO}_{2}$ for $\theta=1$, a negative enhancement factor is obtained This desorption under the circumstances of having a positive driving force $\left(1-a 2_{x}\right)$ for absorption will be defined as forced desorption A consequence of the possible occurrence of forced desorption due to simultaneous absorption of another reactive species is that for such systems the sign of the driving force is no exclusive indication of the direction in which mass transfer will go

Supplementary to counteracting effects at simultaneous mass transfer cooperative effects may also occur

Figure 8 shows the dependence of one particular curve of Figure 1, , e for $\alpha 1=025$ on the value of $K_{\mathrm{CO}_{2}}$ under the following conditions $\alpha 2=025, M=001$ and $p 3=0$

The corresponding desorption curves for $\phi_{2}$ have also been drawn Since $M$ equals 001 , hardly any effects of the $\mathrm{CO}_{2}$ kinetics can be expected Indeed $\phi_{2}$ equals unity and up to $K_{\mathrm{H}_{2} \mathrm{~S}}=90000 \phi_{1}$ can be calculated from Onda's solution [17], similar to the single mass transfer of $\mathrm{H}_{2} \mathrm{~S}$ described above (Table 1, Scheme 3) For this case, $K_{\mathrm{CO}_{2}}$ influences $\phi_{1}$ only v1a the bulk composition

However for $K_{\mathrm{H}_{2} \mathrm{~S}}>90000$ again reversibility effects in the mass transfer zone show up The amine depletion conditions near the interface, dictated by the degree of irreversibility of the $\mathrm{H}_{2} \mathrm{~S}$ reaction (I), cause the desorption of $\mathrm{CO}_{2}$ to be unexpectedly enhanced, or even infinitely enhanced, although its dimensionless reaction rate constant has a small value Infinitely enhanced desorption of $\mathrm{CO}_{2}$ occurs for extremely large values of $K_{\mathrm{H}_{2} \mathrm{~S}}$ This can be defined as infinitely over enhanced desorption The numencally calculated limiting value of $\phi_{2}$ is equal to the theoretically expected value for the case when $\mathrm{CO}_{2}$ desorption is controlled by the supply of $p 2$ from the bulk to the interface

$$
\phi_{2}=1+\frac{p 2_{\infty} A m}{\left(a 2_{\infty}-1\right) m_{2}\left[\mathrm{CO}_{2}\right]_{\mathbf{g}}}
$$

In agreement with this we calculate the limit value $\phi_{1}$ as also equal to the theoretical value

$$
\phi_{1}=1+\frac{\left(b_{\alpha}+2 p 2_{\infty}\right) A m}{m_{1}\left[H_{2} \mathrm{~S}\right]_{g}}=2003
$$

Since the values of $p 2_{\infty}$ and $a 2_{\infty}$ are a function of $K_{\mathrm{CO}_{2}}$, we obtain different limit values of $\phi_{2}$ for every $K_{\mathrm{CO}_{2}}$
The limit value of $\phi_{1}$, however, does not vary with $K_{\mathrm{CO}_{2}}$ since for the present conditions and infinite values of $K_{\mathrm{H}_{2} \mathrm{~S}}$, the sum of $b_{\gamma}$ and $2 p 2$, is equal to $(1-\alpha 1)$

The latter value is also the limit value for the case where $\mathrm{H}_{2} \mathrm{~S}$ absorbs irreversibly and $\mathrm{K}_{\mathrm{CO}_{2}}$ equals zero

Analogous to Fig 8 we could show additional curves for $M=10,100$ etc We think, however, that generating more curves will not contribute any further to showing the excellent behaviour of the discretized system, nor would it illustrate the validity of other approximate models more exclusively Moreover these curves are so complex, by showing asymptotes for cases where one gas component is in equilibrium with the liquid bulk, while the other gaseous component still causes mass transfer for both gases, that this would need excessive explanation We therefore finalize this contribution by showing only Figs 9-11 to illustrate the chemical behaviour

\section{CONCLUSIONS}

The discretization technique presented makes it possible to calculate mass transfer behaviour of a typical, highly complicated chemical sorption/react1on system, without convergence or stability problems over a wide range of conditions The difference between the numerically obtained solutions and those of previous workers was less than $1 \%$ for those cases where exact analytical solutions were avallable As can be expected, the previously published approximate solutions, obtained via linearization tcchniques, differ somewhat more (up to $7 \%$ ) but the agreement was st1ll remarkable

Further, 1t has been shown that the (approximate) solutions for absorption calculations are also valıd for desorption At simultaneous mass transfer special attention has been paid to the reversibility effects in the mass transfer zone It has been shown how negative enhancement factors can occur for conditions when the absorption of one of the gases forces the other to desorb by induced reversibility in the liquid transfer zone, though the driving forces would predict that both gases would absorb This implies that at simultaneous absorption of two gases accompanied by interfering reactions the sign of the driving forces alone does not ensure the direction of mass transfer

By forced transfer zone conditions desorption might occur It has been supplementarly demonstrated that at sumultaneous absorption and desorption, the absorbing component can also actıvate, 1 e "overenhance" and even infinitely overenhance, the desorbing one

It may be concluded from this contribution that the avallability of a stable discretizations technique not only makes it possible accurately to calculate mass transfer behaviour for a very complex reactıng system. thus avoiding possible miscalculation by using linearization techniques, but may also reveal new insights into sorption behaviour 


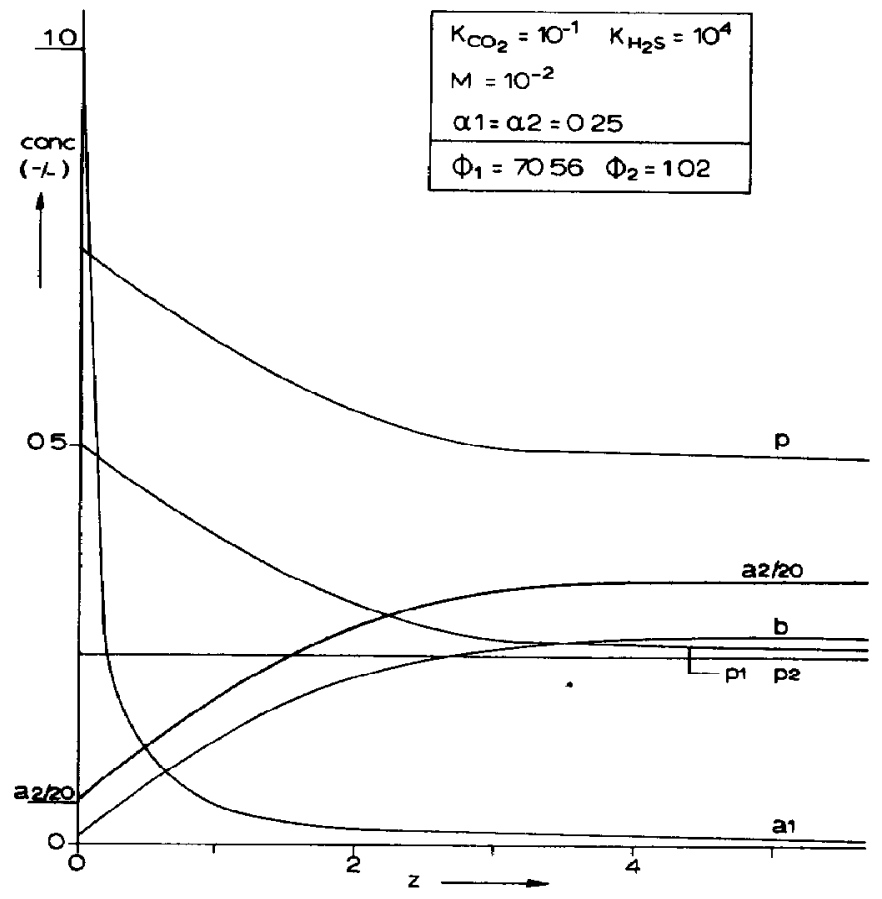

Fig 9

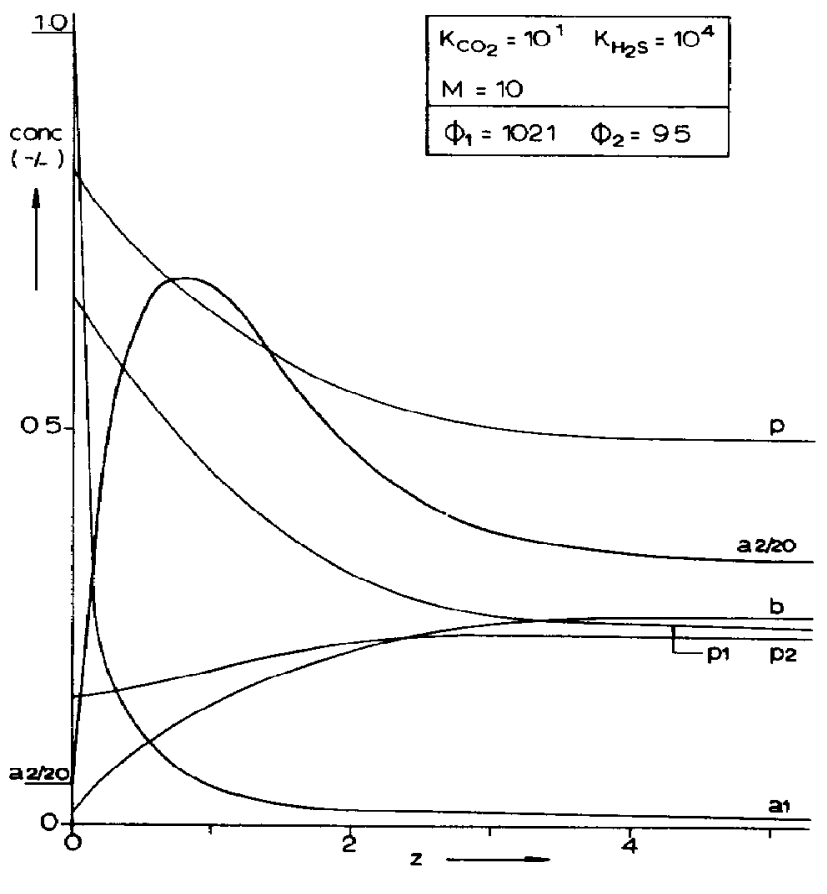

Fig 10

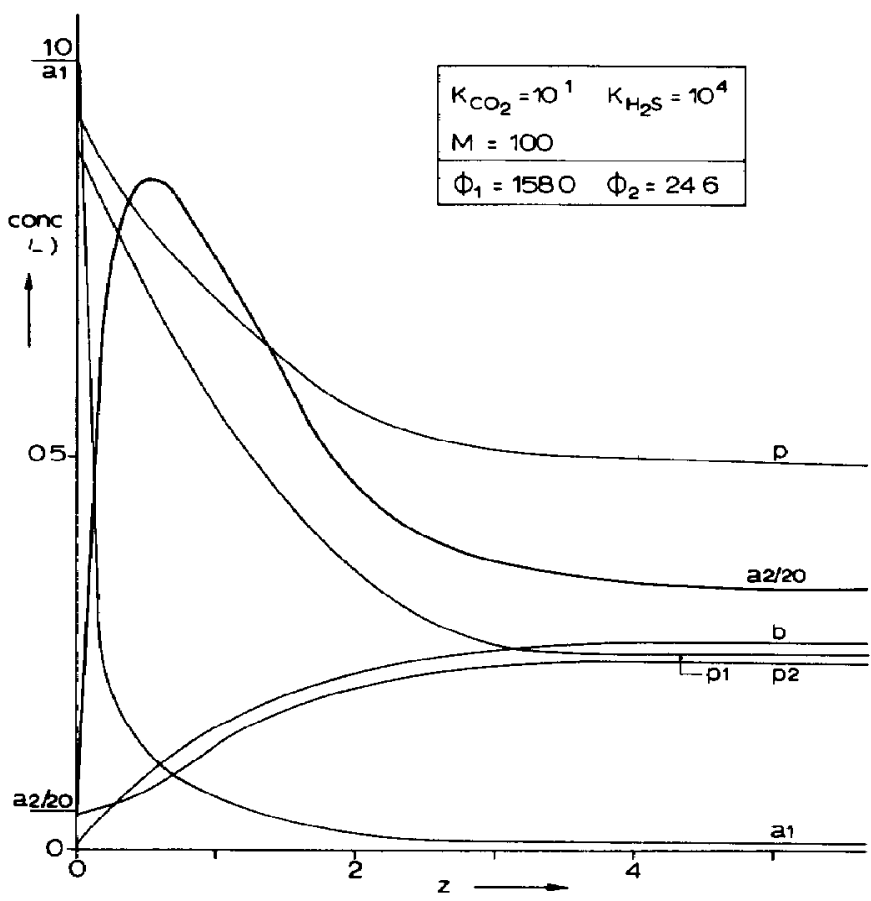

Fig 11

Figs 9-11 Pictures of the numerically calculated dimensionless concentration profiles in the liquid at simultaneous transfer of $\mathrm{H}_{2} \mathrm{~S}(a 1)$ and $\mathrm{CO}_{2}(a 2)$ accompanied by reactions Figure 9 shows the profiles for one particular condition of Figure $8\left(M=10^{-2}\right)$ for curve 5 Figures 10 and 11 show the effect of an increase in $M$ on the profiles and enhancement factors 


\section{NOTATION}

$A$ coefficient matrix defined in eqn (23)

$a 1, a 2 \quad\left[\mathrm{H}_{2} \mathrm{~S}\right] /\left(m_{1}\left[\mathrm{H}_{2} \mathrm{~S}\right]_{\mathrm{g}}\right),\left[\mathrm{CO}_{2}\right] /\left(m_{2}\left[\mathrm{CO}_{2}\right]_{\mathrm{g}}\right)$

Am total amine concentration, see eqn (11)

$b \quad\left[\mathbf{R}_{2} \mathrm{NH}\right] / \mathrm{Am}$

$B$ concentration vector defined in eqn (23)

$C 1, \mathrm{C}_{2}$ total $\mathrm{H}_{2} \mathrm{~S}$ conc, eqn (9), total $\mathrm{CO}_{2}$ conc, see eqn (10)

$D$ liquid diffusion coefficient of component $t$

$h$ distance step in the liquid

$k$ time step in penetration period

$k_{2}$ reaction rate constant

$k g_{1} \quad k_{2}$ mass transfer coefficient of $\mathrm{H}_{2} \mathrm{~S}$ and $\mathrm{CO}_{2}$ respectively in gas phase

$k l_{1}, k l_{2} \quad$ Idem in the liquid phase $\left(=2 \sqrt{ } D_{\mathrm{CO}_{2}} /(\pi \tau)\right.$

$$
2 \sqrt{D_{\mathrm{H}_{2} \mathrm{~S}} /(\pi \tau)}
$$

$K_{2}$ equilibrium constant of reaction species $I$

$K_{1}, K_{2} \quad q 1 / K_{\mathrm{H}_{2} \mathrm{~S}} \quad q 2 /\left(\mathrm{K}_{\mathrm{CO}_{2}} \mathrm{Am}\right)$

$p, p l \quad\left[\mathrm{R}_{2} \mathrm{NH}_{2}^{+}\right] / 4 m,\left[\mathrm{HS}^{-}\right] / A m$

$p 2, p 3\left[\mathrm{R}_{2} \mathrm{NCOO}^{-}\right] / A m,\left[\mathrm{HCO}_{3}^{-}\right] / A m$

$m_{1}, m_{2}$ physical equilibrium constant of $H_{2} S$ and $\mathrm{CO}_{2}$ respectively defined as conc in the liquid phase over that in the gas phase

$M \pi k_{2} \tau A m / 4$

$\mathscr{O}(h, k)$ order symbol quantity roughly proportiondl with $h$ and $k$

$q_{1}, q_{2} A m /\left(m_{1}\left[\mathrm{H}_{2} \mathrm{~S}\right]_{g}\right), A m /\left(m_{2}\left[\mathrm{CO}_{2}\right]_{g}\right)$

$r$ unspecified constant

$r_{t} \quad D_{1} / D_{\mathrm{CO}_{2}}$

$\boldsymbol{R}$ net conversion rate per unit volume

$t$ time variable

$U^{J}$ concentration vector $U$ evaluated at $t$ distance steps and $J$ time steps

$x$ distance variable

$z 2 x / \sqrt{\pi \tau D_{\mathrm{CO}_{2}}}$

Greek symbols

$\alpha, \beta$ unspecified constants

$\alpha 1, \alpha 2 C 1 / A m, C 2 / A m$

$\phi_{1}, \phi_{2}$ enhancement factors defined by eqns (18) and (19)

$\tau, \theta$ contact time according to the Higbie model $t / \tau$

$\xi(z)$ transformation function of distance parameter $z$

$\omega(\phi)$ transformation function of time parameter $\theta$

Indlces

$\begin{aligned} g & \text { gas phase } \\ l & \text { liquid phase } \\ o & \text { at the interface } \\ \infty & \text { at infinite depth in the liquid } \\ {[] } & \text { concentration }\end{aligned}$

REFERENCES

[1] Goettler L A and Pigford R L, I Chem E Symp Ser 196828

[2] Olander O R, A I ChE J 19606233
[3] Onda K, Sada E, Kobayashı T and Fujıne M, Chem Engng Sci 197025761

[4] Onda K, Sada E, Kobayashı $T$ and Fujıne $M$ Chem Engng Scl 1970251023

[5] Onda K, Sada E, Kobayashı T and Fujıne M, Chem Engng ScI 197025753

[6] Onda K Sada E, Kobayash $T$ and Fujne M, Chem Engng Sct 197126247

[7] Ouwerkerk C I Chem E Symp Ser 19682839

[8] Ramachandran $\mathbf{P} A$ and Sharma M M Chem Engng Scl 1972271807

[9] Ramachandran P A and Sharma M M Chem Engng Sct 197126349

[10] Ramachandran $\mathbf{P} \mathbf{A}$ and Sharma $\mathbf{M}$, Trans Instn Chem Engrs 197149253

[11] Shah Y T and Sharma M M, Trans Instn Chem Engrs 1976541

[12] Hikıta H and Asaı S, Kagaku Kogaku 196327823

[13] Van Krevelen D W and Hoftıjzer P J Rec Trav Chım 194867563

[14 ] Cornelisse R, Beenackers A A C M and Van Swaay W P M, Chem Engng Scl 1977331532

[15] Goettler L A and Pigford R L , A I Ch E J 197117793

[16] Danckwerts P V and Sharma M M ,Chem Engng 1966 10244

[17] Ouwerkerk C. Paper presented at Natural Gas Pricessing and Utilization Conference, Dublin 1976

[18] Ouwerkerk C, Hvdrocarb Proc 1978489

[19] Danckwerts P V , Gas-Liquid Reactions, McGraw-Hill. New York 1970

[20] Danckwerts P V and McNell K M, Trans Instn Chem Engrs 19674532

[21] Astarita G, Gioia F and Balzano C Chem Engng $S_{c \iota}$ 1965201101

[22] Gio1a F Chim Ind 1967, 49(9) 921

[23] Tavares da Silva A and Danckwerts P V, Instn Chem E Symp Ser 19682848

[24] Baker G A and Oliphant T A, Quart Appl Math 1960 17(4) 361

[25] Stoer J, Emfuhrung in die Numerische Mathanatik I, p 192 Springer Verlag, Berlın 9716

[26] Secor R M and Beuttler J A, A I Ch E J 196713365

[27] De Coursey W J, Chem Engng Sct 1974291867

[28] Wellek R M, Brunson $R \mathrm{~J}$ and Law $F \mathrm{H}, \mathrm{Can} J$ Chem Engng 197856181

[29] Yeramian A A, Gottifredı J C and Ronco J J, Chem Engng Sct 1970251622

[30] Danckwerts P V, Chem Engng Scl 1968231045

(A2) (7-5-8)

\section{APPENDIX I}

After rearrangement of the original set of eqns (4)-(17) (as indicated between the brackets) a new set of cimensionless differential equations can be denoted (A1)-(A16), which is surtable for numerical treatment

$$
\begin{aligned}
& \frac{1}{q_{1}} \frac{\partial a 1}{\partial \theta}+\frac{\partial p 1}{\partial \theta}=\frac{4}{\pi}\left\{\frac{r_{a 1}}{q_{1}} \frac{\partial^{2} a 1}{\partial z^{2}}+r_{p 1} \frac{\partial^{2} p 1}{\partial z^{2}}\right\} \\
& \frac{\partial b}{\partial \theta}-\frac{2}{q_{2}} \frac{\partial a 2}{\partial \theta}-\frac{1}{q_{1}} \frac{\partial a 1}{\partial \theta} \\
& =\frac{4}{\pi}\left\{r_{b} \frac{\partial^{2} b}{\partial z^{2}}-\frac{2}{q_{2}} \frac{\partial^{2} a 2}{\partial z^{2}}-\frac{r_{a 1}}{q_{1}} \frac{\partial^{2} a 1}{\partial z^{2}}\right\}
\end{aligned}
$$

(A2) $(7-5-8)$

$$
\frac{1}{M} \frac{\partial a 2}{\partial \theta}=\frac{4}{\pi} \frac{1}{M} \frac{\partial^{2} a 2}{\partial z^{2}}-a 2 b+K 2 p 2 p / b
$$




$$
\begin{aligned}
\frac{\partial p}{\partial \theta}+\frac{1}{q_{1}} \frac{\partial a 1}{\partial \theta}+\frac{1}{q_{2}} \frac{\partial a 2}{\partial \theta} & \\
=\frac{4}{\pi}\left\{r_{p} \frac{\partial^{2} p}{\partial z^{2}}+\frac{r a_{1}}{q_{1}} \frac{\partial^{2} a 1}{\partial z^{2}}+\frac{1}{q_{2}} \frac{\partial^{2} a 2}{\partial z^{2}}\right\} & \text { (A4) (8) } \\
\frac{1}{q_{2}} \frac{\partial a 2}{\partial \theta}+\frac{\partial p 2}{\partial \theta}=\frac{4}{\pi}\left\{\frac{1}{q^{2}} \frac{\partial^{2} a 2}{\partial z^{2}}+r_{p 2} \frac{\partial^{2} p 2}{\partial z^{2}}\right\} & \text { (A5) (5) } \\
b a 1 /(p p 1)=K 1 & \text { (A6) (1) }
\end{aligned}
$$

The boundary conditions at $z=0$ are

$$
\begin{aligned}
& 1-a 2=-m_{2} k l_{1} / k g_{2}\left(\frac{\partial a 2}{\partial z}\right) \\
& 1-a 1=-m_{1} k l_{2} / k g_{1}\left(\frac{\partial a 1}{\partial z}\right)
\end{aligned}
$$

(A8) (14)

$$
\begin{gathered}
r_{b} \frac{\partial b}{\partial z}+r_{p} \frac{\partial p}{\partial z}=0 \\
\frac{\partial p 2}{\partial z}=0 \\
r_{b} \frac{\partial b}{\partial z}+r_{p 1} \frac{\partial p 1}{\partial z}=0
\end{gathered}
$$

and at $(\theta=0, z \neq 0)$ and $(\theta \neq 0, z=\infty)$

$$
\begin{gathered}
p^{2}+a 2 / q_{2}=\alpha 2 \\
p 1+a 1 / q_{1}=\alpha 1 \\
b+p 2+p=1 \\
a 2 b^{2} /(p p 2)=K 2 \\
b a 1 /(p p 1)=K 1 \\
p 2+p 1+p 3=P
\end{gathered}
$$

(A10) (16)

(A11) (17)

(A12) (9)

(A13) (10)

(A14) (11)

(A15) (2)

(A6) (1)

(A16) (12) 